Portland State University

PDXScholar

Spring 11-17-2017

\title{
Assessing the Impact of Land Use and Travel on Carbon Dioxide Emissions in Portland, Oregon
}

Zakari Mumuni

Portland State University

Follow this and additional works at: https://pdxscholar.library.pdx.edu/open_access_etds

Part of the Atmospheric Sciences Commons, Transportation Commons, and the Urban Studies Commons

Let us know how access to this document benefits you.

\section{Recommended Citation}

Mumuni, Zakari, "Assessing the Impact of Land Use and Travel on Carbon Dioxide Emissions in Portland, Oregon" (2017). Dissertations and Theses. Paper 4063.

https://doi.org/10.15760/etd.5947

This Thesis is brought to you for free and open access. It has been accepted for inclusion in Dissertations and Theses by an authorized administrator of PDXScholar. Please contact us if we can make this document more accessible: pdxscholar@pdx.edu. 
Assessing the Impact of Land Use and Travel on Carbon Dioxide Emissions in Portland, Oregon

by

Zakari Mumuni

A thesis submitted in partial fulfillment of the requirements for the degree of

\author{
Master of Urban Studies \\ in \\ Urban Studies \\ Thesis Committee: \\ Jennifer Dill, Chair \\ Liming Wang \\ Jenny Liu
}

Portland State University

2017 


\begin{abstract}
The negative consequences of sprawling metropolitan regions have attracted attention in both academia and in practice regarding how to better design settlements and alter travel behavior in a quest to curtail vehicle emissions. Studies that have attempted to understand the nexus between land use, travel and vehicle emissions have not been able to address the issue of self-selection in a satisfactory manner. Self-selection occurs when households choose their residential location based, in part, on expected travel behavior. This nonrandom experience makes the use of traditional regression frameworks that strongly rely on random sampling, unsuitable. This replication study's purpose was to examine the impact of land use and travel on $\mathrm{CO}_{2}$ emissions using the Heckman (1979) sample selection model in Portland Metropolitan Area. Three research questions guided this study: (1) Does self-selection to drive a motor vehicle lead to reduction in $\mathrm{CO}_{2}$ emissions? (2) Does land use and automobile travel influence the decision to drive after controlling for self-selection? (3) What land use and travel factors determine $\mathrm{CO}_{2}$ emissions after controlling for self-selection? The findings suggest driving has a statistically significant negative effect on estimated $\mathrm{CO}_{2}$ and that most land use variables significantly affect driving behavior.
\end{abstract}




\section{Table of Contents}

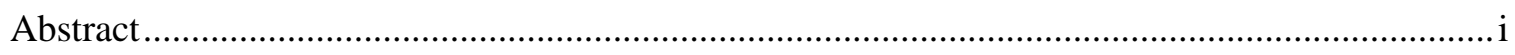

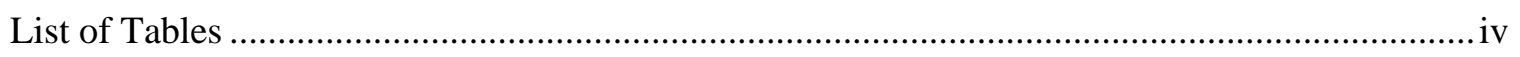

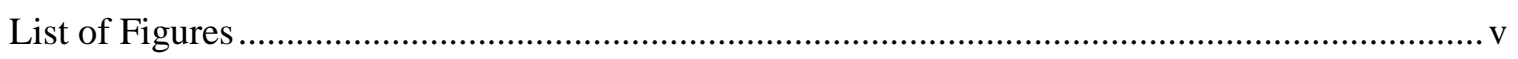

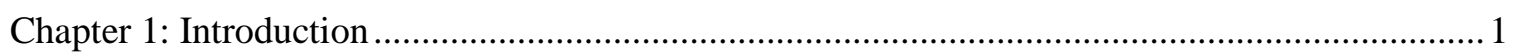

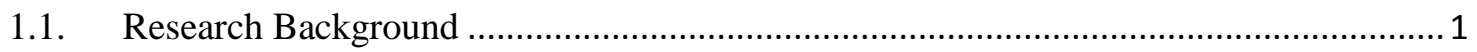

1.2 Conceptual Framework, Research Questions, and Hypotheses .................................... 5

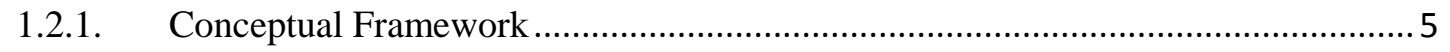

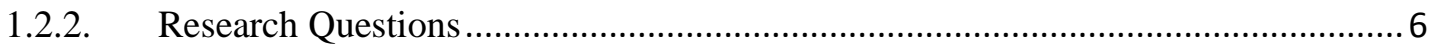

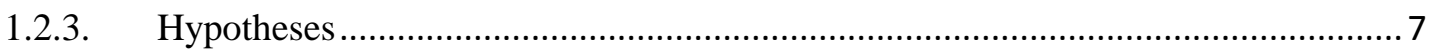

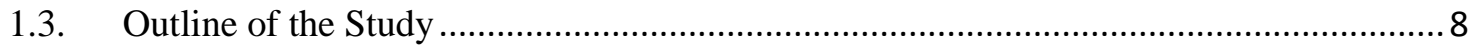

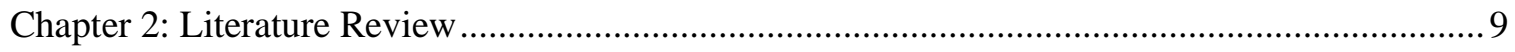

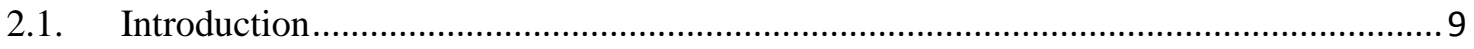

2.2. Residential and Employment Location Choice ......................................................... 9

2.3. Consumer Demand Theory .................................................................................. 11

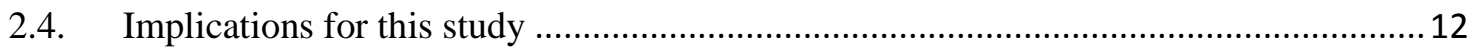

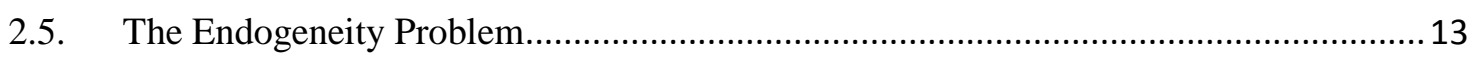

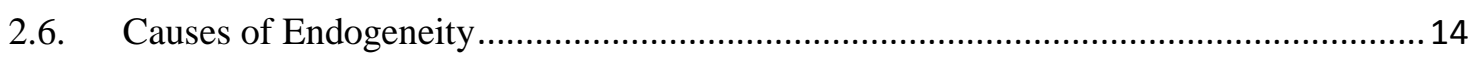

2.7. Econometric Approaches for Addressing Endogeneity ............................................. 15

2.7.1. Heckman Two-Stage Procedure .......................................................................... 16

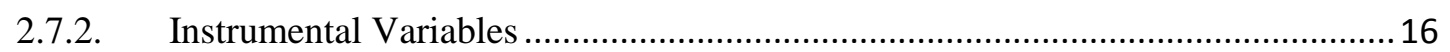

2.8. Impact of Land Use, Travel, and $\mathrm{CO}_{2}$ Emissions ................................................... 18

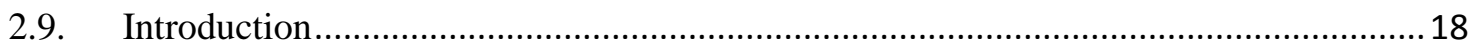

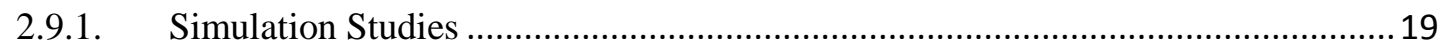

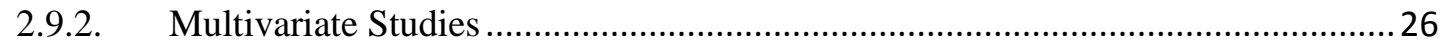

2.9.3. Sample Selection and Instrumental Variable Models ............................................ 31

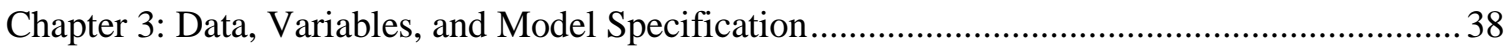

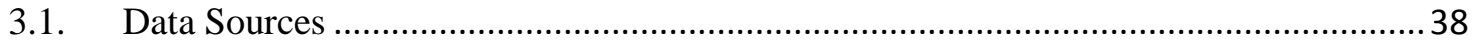

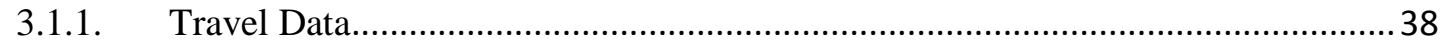

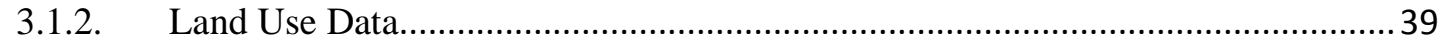

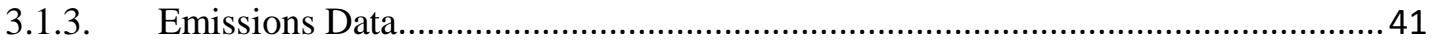

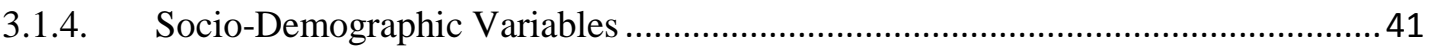

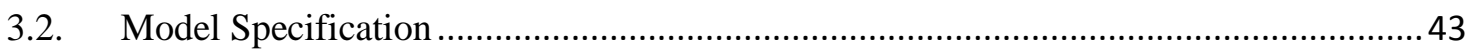

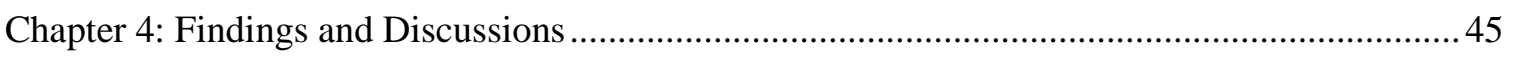




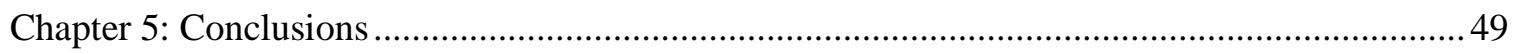

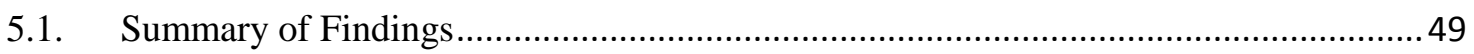

5.2. Research significance for smart growth and climate change ......................................50

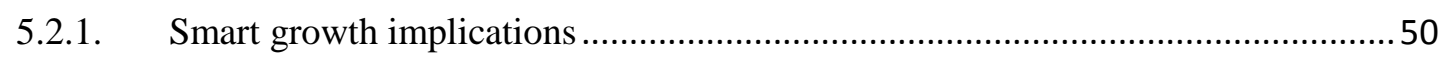

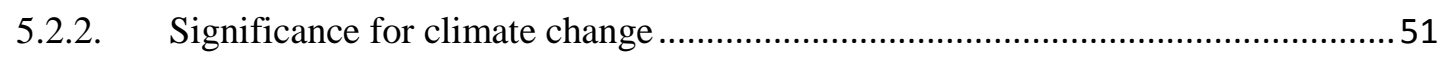

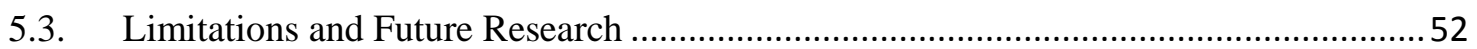

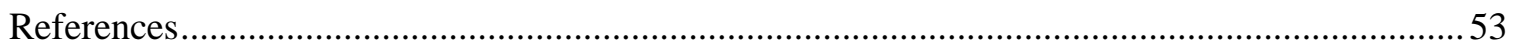




\section{List of Tables}

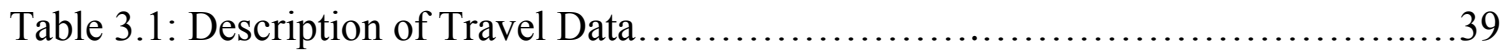

Table 3.2: Description of Land Use Data......................................40

Table 3.3: Summary of Socio-Demographic Variables.............................42

Table 4.1: Heckman Model Results...............................................48 


\section{List of Figures}

Figure 1: Conceptual Framework...............................................6

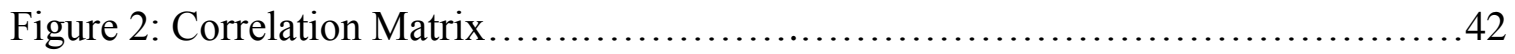




\section{Chapter 1: Introduction}

\subsection{Research Background}

The negative consequences of sprawling metropolitan regions have attracted attention in both academia and in practice regarding how to better design settlements and alter travel behavior in a quest to curtail vehicle emissions. Urban sprawl has been accused of wasting prime lands, increasing congestion and air pollution, and causing obesity (Cox, 2004). Broad separations of land uses through zoning, investment in highways, and government subsidies, among others, have often been cited as causes of urban sprawl. Urban sprawl contributes significantly to transportation-related greenhouse gas (GHG) emissions (Stone et al., 2009). Recently, for example, transportation activities accounted for $25 \%$ of $\mathrm{CO}_{2}$ emissions from fossil fuel combustion (EPA, 2016a).

Metropolitan authorities have been keen on addressing the transportation and land use challenges hindering the achievement of their environmental metrics since, for example,

$37 \%$ of U.S. population lives in a county that violates one or more National Ambient Air Quality Standards (NAAQS) (EPA, 2016b).

Land use policies deemed appropriate in ameliorating transportation impacts include increasing density, mixing land uses, connecting blocks, making destinations accessible, and making transit accessible (TRB, 2009). Land use policies aim to decrease travel demand and emissions by reducing density, trip lengths and encouraging greater transit use, thus resulting in a reduction of carbon dioxide emissions. However, recent work maintains that attempts at increasing density may have negative unintended 
transportation-related environmental consequences such as carbon dioxide (IBI Group, 1990).

The issue of self-selection has become an integral part of assessing the impact of land use and travel behavior on $\mathrm{CO}_{2}$ emissions due to the realization that earlier reliance on land use factors alone to investigate travel and emission outcomes have tended to exaggerate causal effects. Households are deemed to self-select when they choose their residential location based, in part, on expected travel behavior (Boarnet \& Crane, 2001). Empirical findings are inconsistent on the extent that self-selection impacts travel behavior (Bento et al., 2005; Brownstone \& Golob, 2009; Cao, 2009; Cao et al., 2009). The simplest, though impractical, approach to assess travel impacts of land use would be to randomly assign households as either New Urbanist (e.g. compact, diverse and pedestrian-orientated) or suburban (e.g. auto dependent, leapfrogged and uncentered) neighborhoods, and compare the travel outcomes before and after the assignment. Since households cannot be randomly assigned into either neighborhood category because they have already self-selected residential location, random assignment is considered an impractical approach.

Three broad groups of empirical studies have been devoted to assessing the effectiveness of metropolitan initiatives aimed at reducing vehicle emissions. Simulations have often been carried out to examine transportation and emission effects of alternative land use scenarios (Stone et al., 2007; Stone et al., 2009), and found compact developments to reduce auto use and cut $\mathrm{CO}_{2}$ emissions. Although these use unique combinations of land use and travel scenarios to model possible future emissions, the 
comparisons are, at best, descriptive. Others have used multivariate regressions to model the effect of land use and travel variables on vehicle emissions (Frank et al., 2000; Frank et al., 2005), and noted that denser and more mixed land uses led to $\mathrm{CO}_{2}$ reductions. While researcher controlled for personal factors, they did not explicitly account for residential self-selection. Few studies employed sample selection models such as Heckman (1979) and instrumental variables to control for selection bias or endogeneity in land use, travel, and emission models (Wang et al.,2013a). Wang et al. (2013a) used the National Household Travel Survey (NHTS) with Virginia Add-On to determine whether smart growth developments were related to lower $\mathrm{CO}_{2}$ emissions and found that mixed land uses and well-connected roadways were associated with lower $\mathrm{CO}_{2}$ emissions.

This study primarily replicates the above work (Wang et al.,2013a) in Portland Metropolitan Area. Replication is an attempt to extend studies with the aim to externally validate their findings. We can only build confidence in relationships between concepts when such theories have been able to stand the test of falsifications:

Only when certain events recur ... can our observations be tested. We do not take even our own observations quite seriously, or accept them as scientific observations, until we have repeated and tested them. Only by such repetitions can we convince ourselves that we are dealing with a mere isolated "coincidence," but with events which, on account of their regularity and reproducibility, are in principle intersubjectively testable (Popper, 1959, p. 45).

This work extends the work of Wang et al. (2013a) in terms of household residential location, measuring $\mathrm{CO}_{2}$ emissions, the addition of new variables, and 
improved model specification. First, Wang and his colleagues used synthetically imputed residential location at the centroid of census blocks because NHTS did not disclose residential location due to confidentiality concerns. However, work by Wang et al. (2013b) to ascertain validity of geo-imputations in measuring travel behavior noted significant errors when land use variables such as accessibility is measured within census blocks. Second, they failed to compute $\mathrm{CO} 2$ emissions per mile based on type of vehicle. $\mathrm{CO}_{2}$ computations were based on $8,887 \mathrm{~g} \mathrm{CO}_{2}$ per gallon across different vehicle classes which assumed all vehicles in Virginia emitted $\mathrm{CO}_{2}$ at this rate. Third, this work improves previous work by introducing new variables that have higher likelihood of influencing driving decisions and $\mathrm{CO}_{2}$ emissions. These variables include land use (e.g. block size, population density, distance to LRT, distance to bust stop, distance to CBD, number of bus stops, number of LRT stops, and land use mix), demographics (e.g. race, gender, household size, average age of household members, and number of workers), and others (e.g. disability, employer parking, having a transit pass, having flexible work schedules, gas prices, and home ownership). Finally, the study improves the specification of the selection model. Previous work mis-specified the likelihood of driving model by using either land use or travel variables, thereby implying there was no influence of these variables on the decision to drive. Indeed, ample evidence in the literature reviewed point to the relevance of these variables in determining the decision to drive.

This study makes a number of important contributions to research on land use, travel and GHG emissions. First, this study explicitly examines the effect of land use and travel behavior on the decision to drive. This is relevant for travel demand analysts who 
are interested in identifying land uses that significantly impact travel outcomes. Second, this study provides insights into how land uses and travel preferences influence $\mathrm{CO}_{2}$ emissions. This analysis will enhance our understanding of the $\mathrm{CO}_{2}$ emission effects of land use and travel preferences which is vital for planning and managing land use and travel scenarios. Finally, this study will further aid our understanding of air-qualityrelated health effects emanating from land use and travel decisions since vehicle emissions account for most urban air pollution and health threats.

The purpose of this econometric study is to replicate the results of Wang et al. (2013) by examining the impact of land use and travel on $\mathrm{CO}_{2}$ emissions using the Heckman (1979) sample selection model in Portland Metropolitan Area.

\subsection{Conceptual Framework, Research Questions, and Hypotheses}

\subsubsection{Conceptual Framework}

This study is founded on two critical individual decision processes. The underlying assumption is that an individual makes two separate but related decisions with regard to driving. The first decision is whether or not to drive. The second decision is about the level of $\mathrm{CO}_{2}$ emission that is generated once the decision to drive has been made. The decision to drive was thought of being influenced by income (Inc), distance to work (DWork), number of workers (Workers), and the presence of children (Child). All these variables are expected to have a positive relationship with driving. 
The amount of $\mathrm{CO}_{2}$ emitted by households who drive is determined by number of vehicle trips (VTrips), income (Inc), number of vehicles (Veh), number of drivers (Driver), road density (RDen), number of intersections (Int), age of household head (Age) and land use mix (Mix). Figure 1 below shows the conceptual framework guiding this study, adapted from Wang et al. (2013).

Figure 1: Conceptual Framework

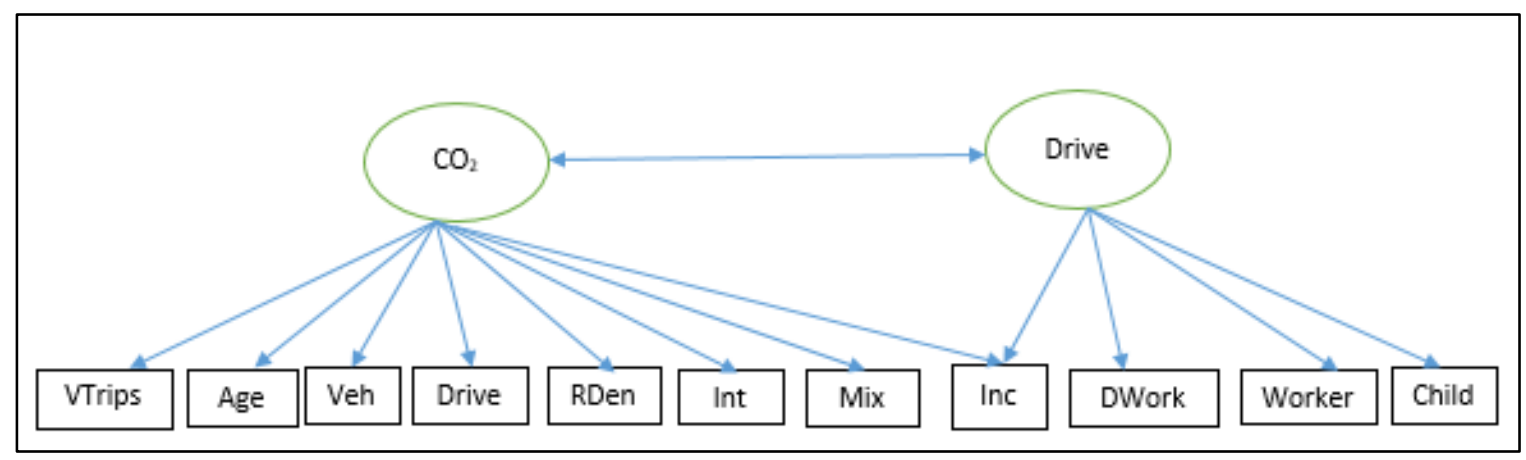

\subsubsection{Research Questions}

The following questions directly follow the conceptual framework above:

Question 1: Does self-selection play a role in the relationship between driving a motor vehicle and $\mathrm{CO} 2$ emissions? If the drivers in the sample randomly chose to drive, an OLS regression could be used to estimate $\mathrm{CO} 2$ emissions. But, drivers who would have high $\mathrm{CO} 2$ emissions may be unlikely to choose to drive, and thus the sample of observed $\mathrm{CO}_{2}$ emission is biased upward. 
Question 2: Does land use and automobile travel influence the decision to drive after controlling for self-selection?

Question 3: What land use and travel factors determine $\mathrm{CO}_{2}$ emissions after controlling for self-selection?

\subsubsection{Hypotheses}

Overall, three hypotheses are tested in this study. The first hypothesis is focused on unobservable factors that affect both the decision to drive and $\mathrm{CO}_{2}$ emissions. That is, it answers the question of whether self-selection is a relevant factor. The second hypothesis is concerned about finding the determinants of the decision to drive. The last hypothesis addresses the effect of land use and travel on $\mathrm{CO}_{2}$ emissions in the presence of self-selection. Following Wang et al. (2013a), the hypotheses driving this study are:

Hypothesis 1: The decision to drive and $\mathrm{CO}_{2}$ emissions are interrelated.

Hypothesis 2: The decision to drive is the result of land use characteristics of households. Hypothesis 3: Land use and automobile travel behavior factors are strongly associated with $\mathrm{CO}_{2}$ emissions. 


\subsection{Outline of the Study}

Chapter two is devoted to reviewing literature germane to the connection between

land use, travel, and $\mathrm{CO}_{2}$ emissions. Chapter three is directed at data, variables, and model specification to address the research questions. Chapter four is dedicated to a report of the findings. Chapter five concludes the study with a summary of the findings and recommendations for future studies. 


\section{Chapter 2: Literature Review}

\subsection{Introduction}

This review is divided into two main sections. The first section is devoted to reviewing relevant underlying theoretical formulations within which the study is conceptualized. The second section looks at endogeneity/self-selection and broad groups of studies that are dedicated to understanding the impact of land use, travel, and $\mathrm{CO}_{2}$ emissions.

\subsection{Residential and Employment Location Choice}

Alonso (1964) is widely accredited with the standard monocentric model of urban land use theory, often referred to as bid-rent theory. This theory derives inspiration from the closed land use and transport model of von Thunen, complementarity model of Wingo, and central place theory of Christaller and Losch. The standard model is a partialequilibrium model because it assumes employment location to be fixed at the central business district (CBD). It also assumes that there is a single-worker in a household, housing cost is a function of capital and land, and transportation cost is constant and uniform across space. Bid-rent theory provides an earlier approach to model residential and firm locations given trade-offs between transportation and housing costs, on one hand, and transportation costs, wages and land rents, on the other. Consequently, bid-rent theory is at the core, a cost-benefit analysis in which residential location choice is based 
on household utility maximization theory while firm location choice is based on profit maximization theory.

Given a household consumption bundle of housing and transportation, households will maximize utility of housing and non-housing goods subject to a budget constraint. A number of stylized facts are discernible from this formulation: that the higher housing cost incurred from locating closer to the CBD is expected to defray the commute cost saved and that the higher the commute distance the lower the housing price. Under this theory, residential densities are expected to decline with distance to CBD because commute costs outweigh rents, thereby showing up in increased trip lengths.

Firms are assumed to locate at places that would maximize profits by either increasing revenue or reducing costs. Since revenue is directly proportional to rent, wages, prevailing price at the $\mathrm{CBD}$ and transportation cost, firms will locate farther from the CBD only if savings in production costs exceed transportation costs of inputs (Pickrell, 1999). Despite the elegance of the standard location theory in predicting residential and employment location, the simplifying assumptions renders the applicability of the model questionable in many urban settings. Changes in contemporary regional environments characterized by decentralized employment, spatial mismatch between jobs and housing locations; household location preferences due to ethnicity and race; and structural changes of dual-income earnings, increased female-headship and increased part-time jobs, continue to make predictions from the bid-rent model unreliable (Giuliano, 1995). 
Cao, Mokhtarian, and Handy (2009) reviewed a large body of literature covering nine methodological categories on residential location and overwhelmingly confirmed the effect of land use on travel choices. Specifically, they noted the decision to choose residential location based on preference for certain travel behavior significantly accounted for some of the variation in the land use-travel connection. Automobile ownership is partially important in the overall effect of residential location on travel behavior. A number of studies have focused on jointly modeling land use and automobile ownership/use. These studies conclude that built environment affects both residential choice and auto ownership (Brownstone \& Golob, 2009; Bhat \& Guo, 2007).

\subsection{Consumer Demand Theory}

Consumer demand theory postulates that demand for a good is directly proportional to characteristics of the good (e.g. price), subject to a budget constraint (Small \& Verhoef, 2007). Boarnet and Crane (2001) formulated a reduced-form microeconomic demand theory to predict travel behavior from prices, income, and sociodemographic characteristics of travelers. Their model defined two key dimensions of a structural model from which the reduced-form is deduced. First, they assumed that land use affects the generalized cost of travel, which is defined as distance and speed between origins and destinations or accessibility. The reasoning here is that compact

developments will shorten trip length and increases travel speeds. Second, they assumed that the cost of travel and socio-economic characteristics determined overall travel 
behavior. While this theory dominates most research assessing the effect of built environment on travel, it has suffered much criticism. Primarily, it suffers from estimation problems such as endogeneity or selection bias (Crane \& Guo, 2011).

\subsection{Implications for this study}

These two theories have important implications for the study of built environment effects on travel. These include density, commuting, and income segregation. Density is one of critical dimensions of urban land use with significant influence on travel. As the city spreads farther from the CBD, the bid-rent model predicts a decline in population density. Increase in commute trip length has been an area of policy concern lately. Glaeser and Kahn (2001) estimated employment and population density gradients for 120 MSAs using zip code level data and found population and employment to be strongly positively correlated. But employment locations were much more centralized than population. This potential mismatch has the tendency to increase distance to work. Income effects of the model are two-pronged. The rich households would prefer to live in the outskirts because of their lower ratio of commute to housing costs. However, the rich could be attracted to locations closer to the center due to their higher opportunity cost of time. Thus, less dense neighborhoods, high income earners living in the outskirts and increase in trip lengths due to separation of residences and workplaces lead to over-reliance on automobiles. 


\subsection{The Endogeneity Problem}

Endogeneity is one of the difficult problems in trying to establish the causal effect of land use on travel. The traditional OLS regression of travel behavior on land use and socio- demographics elicits endogeneity resulting from correlation between the predictors and errors. This endogeneity is the result of the observed proclivity of individuals choosing to live in "locations based on their travel abilities, needs and preferences" (Litman, 2005, p. 6). Thus, individual idiosyncratic attitudes and personal characteristics are fundamental in determining endogeneity. The seminal study of Cervero (1994) regarding the San Francisco Bay Area noted that individuals living in housing developments near transit stations were far more likely to use public transit than average city-dwellers, primarily because "they have a proclivity to patronize rail transit, whether due to habit, personal taste, or happenstance" (p. 177). In a related scenario of individual characteristics determining travel behavior, there is ample empirical evidence to support the notion that an individual's income is a strong predictor of travel mode (Best \& Lanzendorf, 2005; Boarnet \& Sarmiento, 1998). Any attempt at assessing the impact of land use and travel on $\mathrm{CO}_{2}$ emissions without accounting for the unique effect of endogeneity would bias the causal impact. The following subsections examine the sources of endogeneity and possible remedies. 


\subsection{Causes of Endogeneity}

Econometrically, endogeneity is caused by three problems: omitted variables, measurement error, and simultaneity (Wooldridge, 2010, p. 54-55). Omitted variable bias is the situation where an excluded predictor from a regression equation finds itself in the error term to correlate with the remaining predictors. Residential self-selection is a special case of omitted variable bias; the choice of residence is based on factors unobserved by researchers, hence proxying for the unobservable factors captured in the error term. Since predictors of travel behavior would proxy for the unobserved factors due to the correlation with the omitted variables in the error term, the estimated coefficients would not be uniquely measuring the effect of land use on travel behavior. Put differently, because individuals self-select (non-random) residential locations based on attitudes and personal characteristics, the error terms would deviate from random. Thus, unobserved factors erroneously explain the causal effect of land use on travel behavior.

Measurement error arises when predictors in a regression are mismeasured and have additive errors that get subsumed into the error term. Suppose the outcome of interest $y=\beta x+\epsilon(2)$, where $x$ is imperfectly measured by $\tilde{x}=x+u$ (3). Substituting (3) in (2) yields $y=\beta(\tilde{x}-u)+\epsilon=\beta \tilde{x}+(\epsilon-\beta u)$ (4). Therefore, measurement error in the predictor has the tendency to bias the estimates and makes the predictor endogenous. 
Simultaneity bias occurs when a predictor is also caused by an outcome such that $\mathrm{x}$ causing $y$, and $y$, in turn, causes $x$. Suppose the following simultaneous equation for two related processes $X_{i}$ and $Y_{i}$ :

$$
\begin{aligned}
& Y_{i}=\beta_{0}+\beta_{1} X_{i}+u_{i}(5) \\
& X_{i}=\alpha_{0}+\alpha_{1} Y_{i}+v_{i}(6)
\end{aligned}
$$

A reduced-form of substituting one in the other results in:

$$
\begin{aligned}
& Y_{i}=\frac{\beta_{0}+\beta_{1} \alpha_{0}}{1-\alpha_{1} \beta_{1}}+\frac{\beta_{1} v_{i}+u_{i}}{1-\alpha_{1} \beta_{1}}(7) \\
& X_{i}=\frac{\alpha_{0}+\alpha_{1} \beta_{0}}{1-\alpha_{1} \beta_{1}}+\frac{v_{i}+\alpha_{1} u_{i}}{1-\alpha_{1} \beta_{1}}(8)
\end{aligned}
$$

Since neither $Y_{i}$ nor $X_{i}$ can be solved without the other, estimating the structural model with OLS is biased when $X_{i}$ and $u$ are correlated.

\subsection{Econometric Approaches for Addressing Endogeneity}

While at first glance endogeneity seem intractable, advances in econometrics have made it a less difficult issue. There are two ways of handling the problem: the Heckman two-stage procedure and instrumental variables. 


\subsubsection{Heckman Two-Stage Procedure}

Heckman (1979) proposed two equations for dealing with the endogeneity bias in standard regressions: outcome and selection equations. Suppose the outcome $y_{j}$ is determined by $y_{j}=x_{j} \beta+u_{1 j}(9)$ and the selection equation is $z_{j^{\prime} \Upsilon}+u_{2 j}>0(10)$, where $u_{1} \sim N(0, \sigma), u_{2} \sim N(0,1)$, and $\operatorname{corr}\left(u_{1} u_{1}\right)=\rho$. While the Heckman procedure has been widely used in econometrics, its application is challenged when both selection and outcome functions have common variables. In other words, variables that determine the selection equation must be independent of those in the outcome model. The model also assumes outcomes are normally distributed. However, in reality, these two processes may have common predictors. Indeed, Little and Rubin (1987) warns that, "for the [Heckman] method to work in practice, variables are needed in (x2) that are good predictors of $\left(\mathrm{y}^{*}\right)$ and do not appear in (x1), that is, are not associated with (y1) when other covariates are controlled" (p. 230).

\subsubsection{Instrumental Variables}

Instrumental variable estimators are applied to the endogeneity problem by accounting for both observable and unobservable predictors. Recall that endogeneity results from correlation of predictors and errors: 


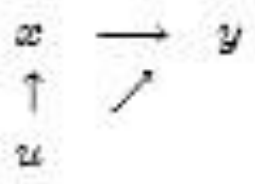

The instrumental variable approach resolves the endogeneity problem by having a variable $z$ (instrument) that correlates with the predictor but not the outcome, as illustrated below:

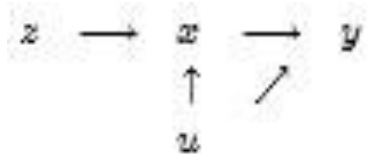

Instruments are derived from a "combination of institutional knowledge and ideas about the processes determining the variable of interest" (Angrist \& Pischke, 2008, p. 117). The process is implemented in two stages, hence two-stage least squares (2SLS). The first step isolates part of the predictor that correlates with the error by regressing predictors on the instrument through OLS. Predicted values of the endogenous predictor are used in the second stage rather than the actual endogenous variables to predict outcomes. The estimated coefficients are unreliable when the instruments are associated with predictors (Wooldridge, 2010, p. 940).

Self-selection bias is a serious concern for evaluating the impact of land use and travel on $\mathrm{CO}_{2}$ emissions. Evaluation methods such as Heckman two-steps and instrumental variables methods for dealing with self-selection and endogeneity are were reviewed. While the Heckman model is important for addressing unobservable variables that affect outcome and selection equations, its application in situations where the outcome of interest is discrete is complex (Greene, 2012, p. 881). Instrumental variables 
that correct self-selection bias in land use and travel studies are mostly weak because they are found to correlate outcomes (Greenwald \& Boarnet, 2001).

\subsection{Impact of Land Use, Travel, and $\mathrm{CO}_{2}$ Emissions}

\subsection{Introduction}

The strength of the relationship between land use, transportation, and mobile source emissions is less straightforward. Studies that link land use, transportation and emissions can be grouped into three main categories: simulations, multivariate, and selection/instrumental variable models.

Simulation studies come in two varieties. One approach is to use median household income, vehicle ownership, and employment rate to determine local VMT estimates, which are passed onto EPA's emission simulators (e.g. Motor Vehicle Emission Simulator, MOVES) to estimate $\mathrm{CO}_{2}$ emissions (Stone et al. 2007; Stone et al. 2009). Another way is to perform integrated land use, transportation, and emission modeling using operational models such as TRANUS (Bandeira et al. 2011) or postprocess the outputs in another simulator to obtain emission values (Mitchell et al. 2011). There are also those studies which rely heavily on standard cross-sectional multivariate techniques, where mobile emission values- based on standard elasticities- are regressed on land use and/or transportation variables (Pushkar, 2000; Frank et al. 2000; Frank et al. 2005). 


\subsubsection{Simulation Studies}

The results from integrated land use, travel, and emission simulations have not been consistent. A review of compact growth and emissions by Bartholomew (2007) showed wide variation in $\mathrm{NO}_{\mathrm{x}}$ emission effects because most studies only use density as the land use variable in predicting travel behavior at the expense of other land use variables. Stone et al. (2007) examined the connection between land use and air quality in 11 MSAs in the upper Midwest of the US under BAU and compact growth (CG) scenarios. For the BAU scenario, the variables of historical growth rates of total population, population density, number of households, median household income, mean vehicles per household, and employment rate projected population and land use in 2050. Under the CG scenario, population growth shifted between rural, urban and suburban areas to reflect containment goals. The CG scenario's growth, based on the BAU scenario, was adjusted with Portland's historical rates.

Vehicle miles traveled is mostly post-processed in MOBILE 6 for modeling emissions for carbon monoxide $(\mathrm{CO})$, nitrogen oxides $\left(\mathrm{NO}_{\mathrm{x}}\right)$, fine particulate matter (PM2.5), and volatile organic compounds (VOC). MOBILE 6 estimates average emission factors per mile per pollutant given variables such as vehicle fleet characteristics, engine mode of operation, climate, and travel speeds. Carbon dioxide emissions $\left(\mathrm{CO}_{2}\right)$ were estimated using average travel speeds and vehicle fuel efficiencies. Using national data, they estimated the number of trips generated and miles of travel for rural, urban and suburban areas using variables such as income, vehicle ownership, and employment rate. 
Number of trips generated and miles of travel were multiplied by number of households to obtain total daily vehicle miles of travel for census tracts. There was some correlation between emissions and the scenarios considered. Specifically, the CG scenario led to $6.0 \%$ reduction in $\mathrm{PM} 2.5,5.6 \%$ in $\mathrm{NO}_{\mathrm{x}}$ and $\mathrm{CO}$, and $5.2 \%$ in $\mathrm{VOC}$ emissions.

Stone et al. (2009) set out to understand land development and vehicle fleet hybridization on emissions in six Midwestern states: Illinois, Indiana, Michigan, Minnesota, Ohio, and Wisconsin. This work differs from the earlier study in the modeling of $\mathrm{CO}_{2}$ emissions. While the earlier study estimated emissions from average speeds and fuel economy standards, the latter study refines the $\mathrm{CO}_{2}$ estimates with the standard 8877 g emission rate. They defined four scenarios consistent with their study 2050 objectives. These were business-as-usual (BAU), Smart-Growth 1 (SG 1), Smart-Growth 2 (SG 2), and Hybrid-Electric Vehicle Fleet Scenario (HEV).

The BAU scenario assumed population and land use changes to be the same as observed trends, resulting in an increase of fuel economy from 19.5 to 25.6 MPG. The SG1 was based on the assumption that additional population growth will only occur in suburban and urban areas through the implementation of regionwide urban growth boundaries (UGB) and transit-oriented development (TODs). Under SG2, some population growth was allowed in the rural fringes, but most growth occurred in suburban and urban areas. The HEV scenario assumed $100 \%$ of a region's vehicular fleet would be converted to HEV, resulting in average fuel economy of 33.0 MPG. Emission adjustment factors were estimated for these scenarios using ratio of base MPG and expected MPG under HEV with a VMT rebound correction of 2\%. The rebound takes into account VMT 
increases due to improved fuel economy. The results indicated that the increase in average fuel economy from 19.5 to $25.6 \mathrm{MPG}$ led to a reduction of $\mathrm{CO}_{2}$ emissions between $5 \%$ and $18 \%$, depending on the scenario.

Bandeira et al. (2011) assessed the effect of land use and transportation emissions in the city of Aveiro, located in the north-center region of Portugal. They employed an integrated approach to land use, transportation and emissions with TRANUS (de la Barra, 1989) and Transport Emission Model (TREM). TRANUS is designed with multiple theoretical foundations. It relies on Alonso's (1964) bid-rent theory, Lowry's (1964) gravity model, Wilson's (1970) spatial interaction model, Leontief's (1951) input-output model, McFadden's (1974) discrete choice model, and Dijkstra's (1959) shortest-path trip assignment algorithm. TREM calculates emission rates of pollutants for CO, PM10, VOC and $\mathrm{NO}_{\mathrm{x}}$. Fuel consumption was calculated using average speed from TRANUS. Land use and transportation of the urban system are mutually dependent and modeled in TRANUS using two concepts: location and interaction. Developers supply locations to households and industries given equilibrium land rents. When demand exceeds supply of location, rents increase to clear the market. TRANUS is rightly based on the assumption that interaction between various locations generates travel. When demand for travel is not met by existing infrastructure, travel time increases, hence locations become inaccessible.

The land use model produces locations of activities, required floor space and land rents which are pivoted to the transport model. The transport model defines multiple paths for each O-D pair given transport network, transport services supply, fares, operating costs, values of time and preferences. This model also estimates transport costs 
and accessibility measures. The number of trips, by mode, between a pair of O-D is defined by volume of interaction and accessibility. The transport model separates the number of trips by vehicle, link, route and person. Finally, travel times are adjusted for constraints on capacity. Link-speeds are fed into TREM for emission estimates.

Bandeira et al. (2011) considered three scenarios: base case, sustainable mobility, and stringent Euro 6 policy. The baseline scenario assumed no change to current transportation practices. The second scenario assumed an increase in vehicle occupancy rate through carpooling and other sustainable arrangements. Lastly, all passenger cars were assumed to comply with Euro 6 technology. Overall, emissions were reduced for sustainable mobility and Euro 6 policy. In scenario 1, CO, PM10, VOC and $\mathrm{NO}_{\mathrm{x}}$ emissions by $54 \%, 44 \%, 44 \%$, and $44 \%$, respectively. For scenario 2 , there was reduction of $83 \%$ in $\mathrm{CO}, 95 \%$ in PM10, $87 \%$ in $\mathrm{VOC}$ and $79 \%$ in $\mathrm{NO}_{\mathrm{x}}$.

Mitchell et al. (2011) studied long-term carbon dioxide emissions from transport for different land use strategies in three UK regions using MEPLAN (Echenique, 1994). MEPLAN is a random utility model with network and land-use equilibrium established through congestion delay and Input-Output (IO) models. Therefore, MEPLAN simulates demand and supply of land and transport models in an integrated fashion. The interaction of these equilibrium markets is essential in defining market price of land and congestion. The number of trips in the network was estimated using SATURN, based on trip demand, congestion, and cost. The $\mathrm{CO}_{2}$ emissions were modeled with SMARTNET using link length, vehicle flow and speed, and speed-dependent fuel use and emission factors in 72 classes of vehicles, weight, engine size, and fuel type. 
The scenarios evaluated included BAU, compaction, dispersal and planned expansion. The BAU considers lower highway investment and higher development densities. Compaction policies were expected to have a very high job-housing balance. Dispersal scenarios relaxed stringent zoning to enable realtors to freely develop sites. Planned expansions aim at developing new communities in old neighborhoods closer to rail lines and highways. $\mathrm{CO}_{2}$ reductions were similar among all scenarios. Compared with BAU, compaction led to an increase of $\mathrm{CO}_{2}$ emissions by $2.2 \%$. Under the dispersal scenario, $\mathrm{CO}_{2}$ emissions increased by $2.1 \%$. Planned expansions were found to register $\mathrm{CO}_{2}$ emissions between -0.2 and $0.2 \%$.

While these simulations provided a broad understanding of the magnitude and direction of relationships between various land use policies and transportation-related emissions, the soundness of these studies is as good as the assumptions made (Lucas, 2009), variables used (Handy, 1996), and intended goal of the simulation (Anderson et al., 1996). Since the exact future is always unknown, assumptions are always made when modeling possible future trajectories of a phenomenon. Most of these assumptions are driven by historical approximations of underlying relationships between variables of interest. When data upon which these assumptions are based are not validated, the assumptions emanating thereof may be unreliable. A case in point is the work of Stone et al. (2007) which defined compact growth rates using Portland's historical data. Despite the absence of compact growth trend data for their regions of study, the reliance on data from another region with different socio-economic background is difficult to justify. 
Six urban growth (infill, constant density, low density, medium density, high density, suburban) and three vehicle technology (BAU, fuel-mix, and HEV mix) scenarios were developed by Hankey \& Marshall (2010) to study the impact of urban form, and vehicle and fuel technologies on travel distance and emissions. In agreement with previous studies, they report that rising VKT has the potential to attenuate the emission benefits from technologies such as HEV and lead to an increase in emissions.

Based on 1991 Air Quality Management Plan Los Angeles metropolitan area, Bae (1993) studied the effect of growth management policies on vehicle emissions, and found that transportation, land use and growth management policies are prohibitively expensive to have any significant effect in reducing vehicle emissions. Based on IMULATE, Farber et al., (2009) simulated morning-peak traffic for Hamilton, Canada under base case, urban growth center, general, and combined intensification scenarios. They found positive $\mathrm{NO}_{\mathrm{x}}$ emissions reduction of different land use policies.

Mansfield, Rodriguez, Huegy and Gibson (2015) investigated how urban design improved air quality and health risks in North Carolina using the regional 4-step travel demand model and land use regression model under three scenarios. The base case scenario was based on the assumption that regional growth in land use would depict a dispersed form with low densities, resulting from inadequate investment in mass transit, development of suburban research offices, and central industrial parks. The second scenario, compact growth, re-allocates population and employment from non-urban to urban in case the area implements policies such as density incentives transfer of development rights, and urban growth boundaries. Finally, a sprawling scenario was 
simulated by reallocating population from a sprawl density threshold of 1.75

persons/acre. That is, TAZs with densities above this threshold are located in TAZs with lower densities while maintaining workplace distributions consistent with the base case. The scenarios were fed into the TDM to determine number, length, and types of trips. PM2.5 concentration $(\mu \mathrm{g} / \mathrm{m} 3)$ was regressed on peak AM VKT within 1,000 meter buffer of the center of the eight monitoring stations. The analysis concluded that compact growth decreased PM2.5 concentrations by $0.2 \%$ whereas sprawl increased concentrations by $1 \%$.

These simulations ignore socioeconomic and attitudinal variables that are critical for explaining observed travel behavior. The variables used include age (Newbold et al., 2005), gender (Best \& Lanzendorf, 2005; Dieleman et al., 2002), number of children (Ryley, 2005), and land use and travel attitudes (Schwanen \& Mokhtarian, 2005). Since simulations aim at gauging possible future state-of-affairs, they inherently gloss over real happenings. The assumptions which are supposed to aid in explaining current behavioral relationships are themselves questionable. Moreover, simulation models do not explicitly account for socioeconomic characteristics of households in the models. These limitations have led to modeling land use, transportation, and emissions using multivariate frameworks. 


\subsubsection{Multivariate Studies}

Multivariate regression-based studies aim at predicting mobile-emissions from land use and travel behavior (TB). These regression studies concur with simulation studies on the conclusion that compact development results in less emission compared with conventional neighborhoods.

Multivariate studies on the effect of land use and travel on vehicle emissions first assume that land use policies influence travel behavior (Crane, 2000). In turn, travel behavior affects vehicle emissions. There are disagreements on whether this stylized fact is indeed true. Krizek (2003) and Shen (2000) intimate that households located in different urban environments travel differently, confirming the fact that urban form influences travel behavior. Others, think the observed relationship between urban form and travel behavior may be inflated (Boarnet \& Sarmiento, 1998; Giuliano \& Small, 1993). Despite the divergence of opinion on the relationship, most studies appear to follow the former position. Therefore, it is important to review scholarship on the effect of urban form and VMT, and VMT's influence on vehicle emissions.

\subsubsection{The Effect of Urban Form on VMT}

Land use is traditionally measured with density, design, diversity, distance to transit, and destination accessibility (Transportation Research Board, 2009). A metaanalytic review of 55 studies by Ewing and Cervero (2010) found consistent 
relationships between land use measures and travel behavior. They found somewhat weak negative elasticities for density (0.00 to -0.04), diversity (-0.02 to -0.09), design (-0.12), destination accessibility (-0.05 to -0.22$)$, and distance to transit (-0.05).

Literature is replete with studies that surmise an inverse relationship between density and distance (Brownstone \& Golob, 2009; Heres-Del-Valle \& Niemeier, 2011; Manville \& Shoup, 2005). VMT reduction elasticities of density vary from $0.2 \%$ to $2.7 \%$ by some accounts (Frank, et al., 2011; Spears, Boarnet \& Handy, 2010). Giuliano and Narayan (2003) examined U.S. and U.K. cities to ascertain whether densities influenced commute and non-commute distances. They regressed daily miles traveled on MSA size and population density, gender, age, income, and employment. They found denser cities to have a higher likelihood of generating shorter commute and non-commute trips.

Studies by Næss (2006), Peng (1997), and Krizek (2003) are in agreement with Giuliano and Narayan (2003). Frank and Pivo (1994) studied the extent of land use diversity and commute length in Seattle/Tacoma. Based on a multiple regression, they found that average commute length in well-balanced neighborhoods was one-third shorter than in neighborhoods with very separate uses. Despite the wide variations in densityVMT elasticities, the overwhelming conclusion affirms the notion that living in denser neighborhoods grants households the prospect to reach many destinations in a shorter amount of time.

Susilo and Maat (2007) observed a negative relationship between accessibility and travel time. This relationship is corroborated by others (Crane \& Chatman; 2003; Ewing \& Cervero, 2010). Neighborhoods with traditionally-gridded street designs were 
found to reduce VMT substantially (Handy, Tal \& Boarnet, 2010; Kulash et al., 1990). Finally, Næss et al. (1995) noted a significantly positive relationship between distance from urban center and an individual's travel distance in Oslo, Norway.

\subsubsection{The Effect of VMT on Emissions}

Most of the research linking distance traveled and vehicle emissions are consistent; higher VMT is associated with higher vehicular emissions in urban areas. Barla et al. (2011) studied the effect of land use on $\mathrm{CO}_{2}$ emissions in Quebec, Canada, controlling for driving license status, gender, university diploma, professional, age group, household structure, homeownership and income classes. They found that a unit increase in distance increased $\mathrm{CO}_{2}$ emissions by 300 grams ( $\mathrm{CO}_{2}$ equivalent). Stead (1999) studied the correlation between travel patterns and per capita emissions of carbon dioxide, carbon monoxide, hydrocarbons, nitrogen oxides and particulate matter. Vehicle emission was calculated from vehicle age, fuel type, engine size, engine temperature, and travel speed and vehicle occupancy. The results showed that travel distance by car is significantly correlated with transport emissions. Studies by Ewing (1997) and Difiglio and Fulton (2000) confirm these correlations.

These two strands of relationships provide the conceptual guideposts for multivariate studies on land use, transportation, and emissions. Pushkar (2000) used a simultaneous regression approach to evaluate the GHG emissions from nine hypothetical neighborhoods using travel survey data from the Greater Toronto Area (GTA). They first 
modeled vehicle ownership from variables such as distance to CBD, number of adults per household, household income, daily bus vehicle service hours within $1 \mathrm{~km}$, number of stores within a $1 \mathrm{~km}$ radius, house types mix in neighborhood, housing units in a $1 \mathrm{~km}$ radius, average dwelling unit size, rapid transit station within $1 \mathrm{~km}$, and road type. The predicted values of vehicle ownership were used, among other variables, to calculate automobile VKT. GHG emissions were estimated with $\mathrm{CO}_{2}$ equivalents of $294 \mathrm{~g}$ per VKT for automobiles and $57 \mathrm{~g}$ per PKT for transit.

The three land use scenarios constructed for this study were conventional suburban, medium density development, and neo-traditional development. The conventional suburban scenario exemplified land use in sprawling neighborhoods. Specifically, it comprised of low density, lack land use mix, and not pedestrian-oriented. The neotraditional development design is high transit access, pedestrian and bicyclingfriendly, and was located in high density areas. The medium density development scenario is a midway future between conventional suburban and neotraditional development. They are assumed to have medium-density, low-rise townhouses, and are auto-oriented with some transit access. They found compact development to have between $25 \%$ to $45 \%$ less GHG emissions when compared with conventional neighborhoods.

Frank et al. (2000) used the Puget Sound Transportation Panel Survey to study the relationship between land use, household travel demand, and vehicle emissions, controlling for residential selection. Land use was measured by household density, employment density, census block density, and commute distances. In MOBILE5, $\mathrm{NO}_{\mathrm{x}}$, 
$\mathrm{CO}$, and VOC emissions were estimated with data on vehicle trip generation, vehicle hours of travel, vehicle miles of travel, average trip travel speed, and the mode of engine operation. They modeled household emissions in a multiple regression with emissions as the dependent variable $\left(\mathrm{NO}_{\mathrm{x}}, \mathrm{CO}\right.$, and $\left.\mathrm{VOC}\right)$ and number of vehicles, household size, income class, household density, employment density, block density as independent variables. On the whole, household and employment densities were negatively associated with $\mathrm{NO}_{x}, \mathrm{CO}$, and VOC emissions. On the contrary, commute distance was positively related with $\mathrm{NO}_{\mathrm{x}}, \mathrm{CO}$, and $\mathrm{VOC}$ emissions.

Frank et al. (2005) tried to understand how the number of jobs per sector, density, mixed use, travel time, and distance affect $\mathrm{NO}_{\mathrm{x}}$ emissions using Puget Sound Household Travel Survey. Emissions were estimated by EPA's MOBILE 6.2 using link speeds and distances from the regional travel demand model. They regressed mean daily household vehicle emissions of hydrocarbons $(\mathrm{HC})$ and oxides of nitrogen $\left(\mathrm{NO}_{\mathrm{x}}\right)$ on vehicles per household, persons per household, VMT, net residential density, intersection density, and mixed land use. They found a positive association between household size and income, and mean daily household vehicle $\mathrm{NO}_{\mathrm{x}}$ emissions. Intersection densities, net residential density and mixed use were negatively associated with $\mathrm{NO}_{\mathrm{x}}$ emissions. Finally, an increase in VMT was strongly and positively associated with $\mathrm{NO}_{\mathrm{x}}$ emissions.

Multivariate studies are limited in two respects. First, they fail to model the connection between land and transportation markets explicitly. Modeling the dependency between land use and transportation sectors is important because spatial interaction between land uses determines demand for travel, and accessibility from the transportation 
infrastructure determines interaction between land uses. Second, the use of ordinary least squares regression to model emissions for the entire sample when some households did not drive is lacking. This presents sample selection bias which can be corrected with Heckman (1979) and instrumental variable models.

\subsubsection{Sample Selection and Instrumental Variable Models}

Sample Selection: Endogeneity refers to the fact that an independent variable included in the model is potentially a choice variable, correlated with unobservables relegated to the error term. Sample selection models address the issue of selection bias through Heckman (1979) selection models. Heckman's (1979) sample selection model is often used to correct selection bias where the outcome of interest is observed for only some part of the sample. The truncation of values of the dependent variable leads to violation of two key OLS regression assumptions: homogeneity of variance and independence. The error term is deemed homogenous when predicted variances for outcome variables are equal for all cases (Tabachnick \& Fidell, 2013). Similarly, errors associated with a case are not allowed to correlate with the errors of any other case (Wooldridge, 2010). In the case of a truncated sample, the constant in the regression which ensures that the mean of the variance is zero is no more accurate. Thus, in the presence of self-selection, the error variance is not constant and errors not independently distributed. 
The Heckman selection model is implemented in two steps: outcome and selection stages. The selection model estimates the likelihood of being in the sample while the outcome model estimates the outcome of interest conditional on being included in the sample from the selection model. The selection equation is estimated using a probit while the outcome model is estimated using OLS. The selection equation also outputs the inverse Mills ratio, which is the non-selection hazard correction that considers only those cases surviving at that stage for inclusion in the second-stage.

Wang et al. (2013) were interested in determining whether neighborhoods with smart growth were associated with lower $\mathrm{CO}_{2}$ emissions using NHTS (2009) with a Heckman (1979) selection model. Land use was defined by number of cul-de-sacs, roadway length (miles), connected node ratio, link node ratio, length per node (miles), and mix of land uses. Travel behavior was measured by auto trip frequency and household driver count. VMT for each trip is multiplied by $8,887 \mathrm{~g} / \mathrm{MPG}$ to derive $\mathrm{CO}_{2}$ per mile. The Heckman (1979) model comes with two equations: the outcome and selection. The selection equation is first modeled with probit to determine the probability of driving given a set of covariates. This probability is inputted into the outcome equation to estimate emissions, conditional on being a driver. The results indicated that neighborhoods with diversified land uses were associated with $12 \%$ lower $\mathrm{CO}_{2}$ emissions, compared with neighborhoods with a single land use. In addition, a 0.1 mile increase in mean roadway length per node is associated with $2 \%$ higher $\mathrm{CO}_{2}$ emissions.

Greenwald (2003) was interested in finding out if land use was significant in substituting walking and transit mode shares using 4,235 respondents in the 1994 
Household Activity and Travel Behavior Survey conducted in Portland, Oregon. He grouped neighborhoods into six categories based on residential tenure and pedestrianenvironment factors (PEF). While the focus of the study was not directly targeted at the problem of self-selection, he used the predicted residential choice probabilities into eight outcome models using multinomial logit and proved that residents self-selected into New Urbanist style neighborhoods by substituting walking mode shares. The use of multinomial logit for the outcome model is inconsistent with the original specification of the model by Heckman (1979) that requires the outcome model be continuous. Despite this limitation, the study has highlighted the link between land use and three travel modes. He could have transformed the dependent variable to circumvent Heckman's (1979) restriction on outcomes.

Zhou and Kockelman (2008) studied the effect of neighborhood types on travel in Austin, Texas, using about 1,900 households in the 1998/99 Austin Travel Survey. Households living in the central area and other urban centers were classified as controls while those in the suburbs were classified as treatments. The treatment model was predicted using household size, number of workers, number of children under 5 years of age, household annual income and number of visitors on the survey day. Household VMT was modeled with household size, number of workers, number of children under five years of age, household annual income, proximity to work/school, delivery driver, and neighborhood median income, densities, and employment. They found that self-selection accounted for $10 \%$ to $42 \%$ of the variance of VMT. The Heckman (1979) model is only appropriate when the outcome to be modeled has a normal distribution. VMT, in this 
case, would deviate from normality, hence the unsuitability of the Heckman (1979)

model. A log-transformation of VMT would have justified the use of Heckman (1979)

model.

Instrumental Variable Models: Instrumental variables are used to examine treatment effects in observational studies to correct endogeneity. Endogeneity is problematic for modeling impact of policies when an independent variable is a choice variable and correlates with unobservable factors in the error terms. That is, changes in predictors are associated with changes in both outcome and errors. Thus, predictors are not truly exogenous of outcomes. In this case, a standard OLS approach will be biased in claiming predictors caused the outcome in the presence of these unobservable factors (Greene, 2012). One possible solution is to conduct an experiment that randomly assigns individuals into control and experiment neighborhoods to assess changes in travel behavior and emissions. Since, such pure experiments are both practically and ethically unfeasible, researchers have resorted to using instrumental variables that satisfy two conditions: uncorrelated with the errors but correlated with the endogenous variable.

Boarnet and Sarmiento (1998) collected travel data from 679 individuals in Southern California to investigate the link between neighborhood land-use patterns and non-work trip generation. They used race and age of housing stock as instruments directly in an ordered probit model of number of non-work trips. Generally, they found a negative but significant association between retail employment density and non-work trips. While this study was important in closing the gap in previous studies by focusing 
on non-work trips, the instruments performed poorly for percent of street grid within a quarter-mile of residences and population density.

Still focusing on non-work trips, Greenwald and Boarnet (2001) used the 1994 Household Activity and Travel Behavior Survey in Portland, Oregon, in ordered probit models. Their land use factors included population density, retail employment density, street grid patterns and pedestrian environment factors (PEF). They constructed instrumental variables from income, college education, race, and housing. They found land use effects on non-work walking trips to be largely present at the neighborhood level. Similar to the Boarnet and Sarmiento (1998) study, the instruments were a poor fit for retail density.

Vance and Hedel (2007) were interested in the impact of land use on car use and distance traveled. They used the German Mobility Panel data containing about 4,300 individuals with at least one car. They used the two-part model (TPM), an extension of Heckman's (1979) selection model which avoids the use of IMR. The TPM is the preferred model when the IMR correlates with predictors. Their instruments were age of housing stock, percent of older adults, and percent of immigrants. Both the selection and outcome equations were predicted by commercial density, street density, commercial diversity, walking minutes to public transit stop, gender, education, employment status, distance to work, age, number of young, number of cars, and income. They found that commercial density, street density and access to public transit were significantly but weakly associated with car use. Additionally, the instrumental variables showed some correlation with outcomes, a violation of instrumental variable application. Since the 
choice of either Heckman (1979) or TPM is primarily dependent on the correlation of IMR with predictors, it would have been interesting to juxtapose the TPM results with those from Heckman's (1979) model to assess these correlations. However, it remains unknown if the Heckman (1979) model would have outperformed their TPM model.

Khattak and Rodriguez (2005) examined whether residents of neo-traditional neighborhoods substituted walking for driving as claimed by New Urbanists in Chapel Hill (neo-traditional) and Carrboro (suburban), both in North Carolina. Their binary logit model predicted residential choice from eight attitudinal instruments: backyard, environmental protection, proximity to sidewalk, land consumption, neighbors, space requirements, children's play space, and access to shops. The predicted residential choice probabilities were used in the final negative binomial model with household size as a predictor. After controlling for demographic characteristics and self-selection, they maintained that single-family residents of neo-traditional neighborhoods made significantly fewer car trips and traveled fewer miles, compared to those in the suburbs. While they accounted for the count outcomes using negative binomial regression, there appears to be some association between walking and proximity to sidewalks, a violation of instrument condition. All instrumental variable estimators struggle to meet the stringent condition of correlating with only predictors. In reality, however, the identified instruments are associated with outcomes as well.

In the final analysis, modeling land use, travel, and emissions (LTE) is important in understanding the conditions under which changes in land use and travel necessitate changes in vehicle emissions. Broadly, LTE is modeled with simulations, multivariate, or 
selection/instrumental variable models. Simulations aim at modeling long-term emission effects of land use and travel factors. They mostly use standalone platforms such as TRANUS and MEPLAN to determine link speeds which are fed into an emission simulator such as MOBILE 6.2. Because they are macro-level models, they are unable to ascertain which individual characteristics are important in emission models. Multivariate models are cross-sectional snapshots of vehicle emissions given personal, land use and travel variables. Multivariate models fail to fully account for self-selection. Sample selection models are beginning to offer useful insights in emission models due to censored nature of emission data. Weak instruments render instrumental variables inefficient. 


\section{Chapter 3: Data, Variables, and Model Specification}

This chapter was mainly concerned about sources of data and the process of deriving variables. Also, the chapter looks at specification of the econometric model. A number of data were used for this study. Travel data for Portland Metropolitan Area were obtained from the second wave of Oregon Household Activity Survey (OHAS) launched in 2011. Land use data were procured from OHAS, Regional Land Information System (RLIS), and US Census Bureau. Socio-demographic data were acquired from OHAS.

The OHAS data was collected between April 2009 and November 2011. The goal of collecting this data was to profile demographic and travel characteristics of households in Oregon in an effort to update travel demand models. It contains person, household, trip, and vehicle files. Multiple random samples drawn from address-based sampling frame, supplemental geographic and choice samples, and a small cellular phone sample resulted in 19,932 households, 46,414 persons, and 172,079 trips data.

\subsection{Data Sources}

\subsubsection{Travel Data}

Travel-related variables used for the study were binary driving decision, number of auto trips, number of vehicles in a household, number of drivers, and distance to work, all of which were obtained from OHAS. Table 3.1 below shows the summary statistics of 
travel data. On average, about two vehicles were used to make seven trips. There were about two drivers per household and the distance to work was about five miles.

\section{Table 3.1: Description of Travel Data}

\begin{tabular}{lccccr}
\hline Variable & N & Mean & SD & Min & Max \\
\hline Number of Vehicles & 4394 & 1.8 & 1.0 & 0.0 & 8.0 \\
Vehicle Trips & 4394 & 7.0 & 6.6 & 0.0 & 55.0 \\
Distance To Work & 4394 & 4.9 & 8.8 & 0.0 & 160.4 \\
Number of Drivers & 4394 & 1.7 & 0.7 & 0.0 & 6.0 \\
\hline
\end{tabular}

\subsubsection{Land Use Data}

Land use data surrounding three-quarter mile buffer of the residence of a household was chosen to represent a neighborhood. Land use data included: number of 3 and 4 way intersections, road density, and land use mix. All the variables came from Metro's Regional Land Information System (RLIS). For intersections, I used OpenJump to dissolve the street layer street name and then used Quantum Geographic Information System (QGIS) to count the number of 3 and 4 way intersections within the residential buffer. Road density is defined as the ratio of number of miles of roads to square miles of household residential buffer. QGIS sum line lengths tool was used to get all the lengths of roads within the household residential buffer. Finally, the land use mix was computed from Agriculture, Commercial, Forest, Industrial, Multi-Family Residential, Public/Semi- 
Public, Rural, and Single-Family Residential uses. The level of diversity is conceptualized as a Shannon-Entropy Index that ranges from 0 to 1 , with 1 indicating heterogeneous and 0 homogeneous land uses. Land use mix index was calculated using the following formula (Cervero \& Kockelman, 1997):

Land Use Index $=-\frac{\sum_{i=1}^{n}\left(p_{k} I n p_{k}\right)}{\operatorname{In} N}$

Where $P k$ is the proportion of land use type $i$ of total land area and $N$ is the number of land uses used. Table 3.2 below shows the summary statistics of land use data. On average, there were about 250 intersections within the residential buffer with a minimum of 5 and maximum of about 700 intersections. There was about 20 miles of roads in the residential buffer of each household with a more balanced land use mix (0.8 land use mix value).

Table 3.2: Description of Land Use Data

\begin{tabular}{lrrrrr}
\hline Variable & N & Mean & SD & Min & Max \\
\hline Number of Intersections & 4394 & 247.5 & 123.7 & 5.0 & 700.0 \\
Road Density & 4394 & 19.6 & 6.7 & 0.0 & 38.8 \\
Land Use Mix & 4394 & 0.8 & 0.1 & 0.3 & 1.0 \\
\hline
\end{tabular}




\subsubsection{Emissions Data}

A Carbon Dioxide emission per gallon was divided by MPG for each vehicle to arrive at $\mathrm{CO}_{2}$ emissions per mile. The MPG data was obtained from vehicle file in OHAS. This figure was multiplied by VMT to get $\mathrm{CO}_{2}$ emissions per trip. Different vehicles were assigned different $\mathrm{CO}_{2}$ per gallon depending on their fuel type. The $\mathrm{CO} 2$ per gallon for gasoline and diesel/ flex fuelled vehicles were 8887 and 10180, respectively. On average, each household recorded 33000 grams of CO2. Only 3619 households had data on MPG that was included in the final sample.

\subsubsection{Socio-Demographic Variables}

Socio-demographic factors served as control variables in the econometric model. These variables included age of head of household, number of children, income, and number of workers. All socio-demographic variables were from OHAS. Table 3.3 below shows the summary statistics of socio-demographic data. The average age of head of households was 55 years. Average income stood at $\$ 71000$. The number of workers in each household was 1.3 and about $30 \%$ of households had children. 
Table 3.3: Summary of Socio-Demographic Variables

\begin{tabular}{lrrrrr}
\hline Variables & N & Mean & SD & Min & \multicolumn{1}{c}{ Max } \\
\hline Age & 4394 & 55.0 & 15.4 & 18 & 99 \\
Income & 4394 & 71766.7 & 54152.9 & 0 & 200000 \\
HH Workers & 4394 & 1.3 & 0.8 & 0 & 5 \\
Presence of Children & 4394 & 0.3 & 0.4 & 0 & 1 \\
\hline
\end{tabular}

The figure below shows the correlation matrix of the variables considered for this study.

Figure 2: Correlation Matrix

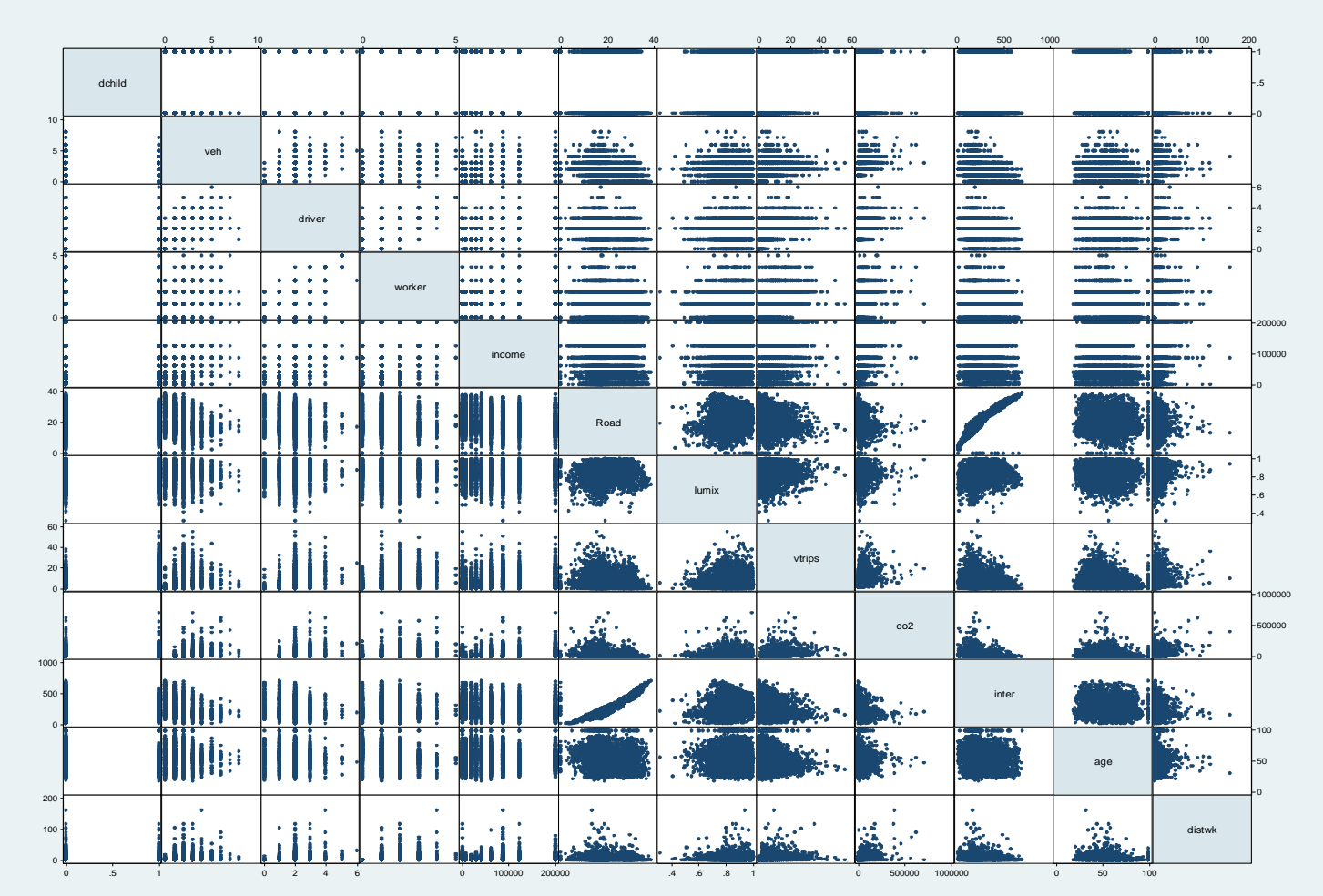




\subsection{Model Specification}

This study employed Heckman (1976) model comprising selection and outcome equations to examine the impact of land use, automobile travel, and $\mathrm{CO}_{2}$ emissions. The

dependent variables for the selection was log-transformed $\mathrm{CO}_{2}$. Carbon dioxide emission was log-transformed to correct the non-normality of its distribution. The independent variables for the selection model were income (Inc), distance to work (DWork), number of workers (Workers), and the presence of children (Child).

The independent variables for the outcome model were number of vehicle trips (VTrips), income (Inc), number of vehicles (Veh), number of drivers (Driver), road density (RDen), number of intersections (Int), age of household head (Age) and land use $\operatorname{mix}(\operatorname{Mix})$.

Mathematically, the specifications outlined below emanate directly from the conceptual framework:

$\log \mathrm{CO}_{2}=\beta_{0}+\beta_{1}$ Vtrips $+\beta_{2}$ Inc $+\beta_{3}$ Veh $+\beta_{4}$ Driver $+\beta_{5}$ RDen $+\beta_{6}$ Int $+\beta_{7}$ Mix $+\beta_{8}$ Age $+u_{1}$ $\mathrm{CO}_{2}$ is assumed to be observed if

$\gamma_{0}+\gamma_{1}$ Inc $+\gamma_{2}$ DWork $+\gamma_{3}$ Worker $+\gamma_{4}$ Child $+u_{2}>0$

The selection and regression equations are linked through their error terms. In the absence of no relationship between the two equations, OLS regression would be efficient since there would not be any self-selection problem. This is the case when $\rho$ (rho) is not 
significant. Marginal effects were reported in terms of a percent change in the dependent variable (coefficient $\mathrm{x}$ 100) for a unit change in the independent variable, all things held constant. The model was implemented with STATA 13 (StataCorp, 2013). 


\section{Chapter 4: Findings and Discussions}

\section{Does self-selection play a role in the relationship between driving a motor vehicle and $\mathrm{CO}_{2}$ emissions?}

The impact of driving on $\mathrm{CO}_{2}$ emissions is well established in the literature. However, these impacts in the presence of self-selection required further investigation. Table 2 reports the results of the Heckman model. This question implies that vehicles driven on the survey day emitted more $\mathrm{CO}_{2}$. The unobserved factors of outcome and selection equations measure the degree of correlation between the factors (rho). Indeed, the result indicates a very high statistically significant correlation between unobserved factors in outcome and selection equations, $p=-0.81, \chi^{2}(1)=299.93$ (prob. $\left.<0.0001\right)$. The negative rho value shows that unobservable factors that make driving more likely tend to be associated with lower $\mathrm{CO}_{2}$ emissions. While unrealistic at a sample level, one should be reminded of the important assumption of rho not equal zero at the population level and not in the sample which has omitted many plausible explanatory variables. Also, the emissions per gallon data from EPA and MPG data may not properly reflect emissions and fuel efficiency in Portland. It would be of utmost importance to consider using alternative methods of deterring emissions for future studies.

\section{Does land use and automobile travel influence the decision to drive?}


Overall, for the selection model, income, distance to work, number of workers, and presence of children were statistically significant at predicting the likelihood of driving at the $5 \%$ level. Specifically, a unit increase in household workers increases the likelihood of driving by $13 \%$, controlling for other variables. Wang et al. (2013) found a similar result (8.6\%). A unit increase in the distance to work increased the likelihood of driving by less than $1 \%$. A unit increase in income increases the probability of driving by less than $1 \%$. Having children in a household increases the likelihood of driving by as high as $14 \%$.

\section{What land use and travel factors determine $\mathrm{CO}_{2}$ emissions after controlling for self- selection?}

For the outcome model, number of vehicle trips (VTrips), number of vehicles (Veh), number of drivers (Driver), number of intersections (Int), age of household head (Age), were statistically significant at predicting $\mathrm{CO}_{2}$ emissions. As expected, a unit increases in vehicle trips increases $\mathrm{CO}_{2}$ emissions by $3 \%$. Having one more vehicle in the household has the potential to increase $\mathrm{CO}_{2}$ emissions by as high as $32 \%$. This is six times higher than found by Wang et al. (2013a) in Virginia. The Portland figures are higher than those in Virginia because Wang et al. (2013a) used the gasoline emission rates for diesel vehicles, thereby underestimating total emissions.

An additional driver in the household increases the likelihood of $\mathrm{CO}_{2}$ emissions by $4.7 \%$. A unit increase in the number of intersections decrease $\mathrm{CO}_{2}$ emissions by less 
than one unit. Having older household heads increases the probability of increasing $\mathrm{CO}_{2}$ emissions by one-half of a percent.

A unit increase in distance to work, distance to CBD and number of vehicles tend to increase $\mathrm{CO}_{2}$ emissions. On the contrary, increase in distance to nearest bus stop had a negative effect of $\mathrm{CO}_{2}$ emissions. A unit increase in distance to work increases the $\mathrm{CO}_{2}$ emissions by $11 \%$. All things being equal, as households drive longer to work, they burn more fuel which generates more $\mathrm{CO}_{2}$. Indeed, average commute time has increased by 1 minute from 2006 to 2014. A unit increase in distance to nearest bus stop decreases the $\mathrm{CO}_{2}$ emissions by $37 \%$.

A unit increase in number of vehicles increases the $\mathrm{CO}_{2}$ emissions by $23 \%$. This is four times higher than found by Wang et al. (2013). 
Table 4.1: Heckman Model Results

\begin{tabular}{|c|c|c|c|c|c|c|}
\hline \multirow[b]{3}{*}{ Variables } & \multicolumn{3}{|c|}{ Outcome } & \multicolumn{3}{|c|}{ Selection } \\
\hline & \multicolumn{3}{|l|}{ Marginal } & \multirow[b]{2}{*}{ B } & \multirow[b]{2}{*}{ SE } & \multirow[b]{2}{*}{$\mathrm{p}>\mathrm{z}$} \\
\hline & Effect & SE & $\mathrm{p}>\mathrm{z}$ & & & \\
\hline Vehicle Trips & 0.290 & 0.001 & $<0.001$ & & & \\
\hline Income & $<-0.001$ & $<0.001$ & 0.051 & $<0.001$ & $<0.001$ & $<0.001$ \\
\hline HH Vehicles & 0.277 & 0.010 & $<0.001$ & & & \\
\hline Diver & 0.046 & 0.015 & 0.002 & & & \\
\hline Road Length & -0.004 & 0.003 & 0.194 & & & \\
\hline Intersections & $<-0.001$ & $<0.001$ & 0.031 & & & \\
\hline Land Use Mix & -0.014 & 0.085 & 0.865 & & & \\
\hline Age of HH Head & 0.005 & 0.003 & 0.048 & & & \\
\hline Age of HH Head Squared & $<-0.001$ & $<0.001$ & 0.039 & & & \\
\hline Distance to Work & & & & 0.111 & 0.009 & $<0.001$ \\
\hline Number of Workers & & & & 0.126 & 0.031 & $<0.001$ \\
\hline Child in $\mathrm{HH}$ & & & & 0.135 & 0.064 & 0.035 \\
\hline Constant & 3.458 & 0.107 & $<0.001$ & 0.124 & 0.044 & 0.005 \\
\hline $\mathrm{N}=4394$ & & Log lik & ihood $=-$ & 8.35 & & \\
\hline Prob. $>$ chi-squared $=0.000$ & & $\rho=-.81$ & 1, probab & $y>$ chi-sc & ared $<.001$ & \\
\hline
\end{tabular}




\section{Chapter 5: Conclusions}

This study has helped to enhance our understanding of the complex relationship between land use, automobile travel, and $\mathrm{CO}_{2}$ emissions. Heckman (1976) model for correcting self-selection was employed to gain additional knowledge in evaluating the impact of land use, travel, and $\mathrm{CO}_{2}$ emissions. Land use, travel, and socio-demographic data from Census Bureau, OHAS, and RLIS were used to conduct this study. This section reports the findings and explores possible future studies given limitations of this study.

\subsection{Summary of Findings}

Three key questions were posed for this study. All the questions were answered in the affirmative.

Question 1: Does self-selection play a role in the relationship between driving a motor vehicle and $\mathrm{CO}_{2}$ emissions? The results indicate the presence of selection, ruling out importance of OLS in modeling land use, automobile travel, and $\mathrm{CO}_{2}$ emissions.

Question 2: Does land use and automobile travel influence the decision to drive? For the selection equation, the most important predictors of driving were number of workers, distance to work, income and presence of children.

Question 3: What land use and travel factors determine $\mathrm{CO}_{2}$ emissions?

Conditional on driving, $\mathrm{CO}_{2}$ emissions were predicted by number of vehicle trips, number of vehicles, number of drivers, number of intersections, and age of household head. 


\subsection{Research significance for smart growth and climate change}

\subsubsection{Smart growth implications}

The findings of this study have potential implications for urban growth management and climate change. Out of the 10 principles identified by The Smart Growth Network to be essential to managing rapid growth of urban neighborhoods in a sustainable manner, 8 are directly related to land use and transportation. These are mixing land uses, compact designs, housing diversity, encourage non-motorized transport, having a sense of place, protection of sensitive environmental resources, and community revitalization. These principles can directly be translated into actionable neighborhood design strategies. These strategies can manifest in street designs, transit-oriented developments (TODs), and sustainable transportation planning. Street designs can be reoriented from primarily serving automobiles to encouraging transit use by, for example, increasing the number of intersections.

Similarly, TODs which are mixed-use developments in close proximity of transit stops can significantly change travel behavior, especially from driving to transit. Well implemented, TODs can help improve air quality, protect open spaces and increase ridership (Cervero, 2004). These developments shorten the distance between residences and workplaces, hence fewer driving trips which generate much of the $\mathrm{CO}_{2}$ emissions. Sustainable transportation is a movement from transport options that worsen pollution, help to reap benefits of non-motorized and transit, and meet sustainable development objectives (Schiller, Bruun \& Kenworthy, 2010). 
Finally, the extent at which transportation system is sustainable can be measured from a wide range of indicators. Some of the proposed sustainable indicators with high impact on transportation include number of trips and modes used (Heanue, 1997), accessibility of employment centers and auto use (Litman, 2007). Thus, making streets complete with other transportation options, mixing uses at transit stations and embracing sustainable transportation reduces driving, hence reduce $\mathrm{CO} 2$ emissions.

\subsubsection{Significance for climate change}

Recent rapid changes in the global climate have attracted concomitant policy and research attention. Although both natural and human actions are responsible for rising temperatures, volcanic eruptions, and natural causes of GHGs (IPPC, 2013 ), most recent increases are directly related to human activities. For instance, in $2014, \mathrm{CO}_{2}$ accounted for about $81 \%$ of total GHG emissions, of which transportation's share was $26 \%$, second to electricity (30\%). This trend can be reversed by, among others, altering land uses so as to reduce auto travel demand and induce transit patronage, thus greatly benefitting the climate.

Land use changes that increase density and mix residential and commerce activities, in combination with accessibility improvements are more likely to reduce $\mathrm{VMT}$ and $\mathrm{CO}_{2}$ emissions. Accessibility could be enhanced by shortening the distance to work through land use mix, shortening distance to transit stops and CBD by encouraging TODs. 


\subsection{Limitations and Future Research}

Like many empirical studies, this work has many drawbacks, among which are not differentiating between work and non-work trips, limited land-use mix measurement, and not accounting for hierarchical relationship between land use and household location. The importance of non-work trips in overall trips is unquestionable. According to NHTS (2009), non-work trips accounted for $89 \%$ of total trips, $84 \%$ of person trips per day, and $81 \%$ of person miles of travel per day. Obviously, concentrating on work trips in this study masks important component of travel- family, personal, social, and recreationalthat can influence $\mathrm{CO}_{2}$ emissions in no trivial way.

The land use-mix index that was constructed focused on horizontal footprint of activities rather than vertical uses. These activities were Agriculture, Commercial, Forest, Industrial, Multi-Family Residential, Public, Rural, and Single Family Residential. This therefore assumed no use beyond ground level for storey buildings. Since land uses such as Commercial, Industrial, Multi-Family Residential, and Public can be mixed up in a single location, it would be interesting to see future work account for their square footage in the land use mix.

Hierarchical modeling of constructs has become appealing for social scientist on statistical grounds. When a number of households share a common land use because they are located with the same neighborhood, standard errors of OLS regressions are underestimated. This has the potential of rejecting the null hypothesis when it cannot be rejected if corrections were made. No studies so far have attempted to combine hierarchical models with sample selection in understanding land use and transportation. 


\section{References}

1000 Friends of Oregon. (1993). Making the Land Use, Transportation, Air Quality Connection. The Pedestrian Environment 4A.

Alonso, W. (1964). Location and Land Use. Harvard University Press, Cambridge, MA. American Planning Association. 2012. Policy Guide on Smart Growth. Retrieved from: http://www.planning.org/policy/guides/pdf/SmartGrowth.pdf. Accessed 2/15/16.

Anderson, W., Kanaroglou, P., and Miller, E. (1996). Urban Form, Energy and the Environment: A Review of Issues, Evidence, and Policy. Urban Studies, 33, 7-35.

Angrist, J. D., \& Pischke, J. S. (2008). Mostly harmless econometrics: An empiricist's companion. Princeton University Press.

Apogee Research, Inc. (1994). Costs and Effectiveness of TCMs: A Review and Analysis of the Literature. Prepared for the National Association of Regional Councils (Washington, DC).

Avin, U. P., \& Holden, D. R. (66). Does your growth smart? Planning, (1), 2000.

Bae, C. (1993). Air Quality and Travel Behavior: Untying the Knot. Journal of the American Planning Association, 59(1), 65-74. http://doi.org/10.1080/01944369308975845

Bandeira, J. M., Coelho, M. C., Sá, M. E., Tavares, R., \& Borrego, C. (2011). Impact of land use on urban mobility patterns, emissions and air quality in a Portuguese medium-sized city. Science of the Total Environment, 409(6), 1154-1163.

Banister, D., Watson, S., \& Wood, C. (1997). Sustainable Cities: Transport, Energy, and Urban Form. Environment and Planning B: Planning and Design, 24(1), 125143. http://doi.org/10.1068/b240125

Barla, P., Miranda-Moreno, L. F., \& Lee-Gosselin, M. (2011). Urban travel CO 2 emissions and land use: a case study for Quebec City. Transportation Research Part D: Transport and Environment, 16(6), 423-428.

Barth, M., An, F., Norbeck, J., \& Ross, M. (1996). Modal emissions modeling: A physical approach. Transportation Research Record: Journal of the Transportation Research Board, (1520), 81-88.

Bartholomew, K. (2007). Land use-transportation scenario planning: promise and reality. Transportation, 34(4), 397-412.

Bento, A. M., Cropper, M. L., Mobarak, A. M., \& Vinha, K. (2005). The effects of urban spatial structure on travel demand in the United States. Review of Economics and Statistics, 87(3), 466-478.

Berke, P. R. (2002). Does sustainable development offer a new direction for planning? Challenges for the twenty-first century. Journal of Planning Literature, 17(1), 2136.

Berke, P., Godschalk, D., Kaiser, E., \& Rodrıguez, D. A. (2006). Urban land use planning. Urbana-Champaign, IL: University of Illinois Press.

Best, H., \& Lanzendorf, M. (2005). Division of labour and gender differences in metropolitan car use: An empirical study in Cologne, Germany. Journal of Transport Geography, 13(2), 109-121.

Boarnet, M. G., \& Crane, R. (2001). Travel by design the influence of urban form on travel. Oxford, NY: Oxford University Press. 
Boarnet, M. G., \& Sarmiento, S. (1998). Can land-use policy really affect travel behaviour? A study of the link between non-work travel and land-use characteristics. Urban Studies, 35(7), 1155-1169.

Brownstone, D., \& Golob, T. F. (2009). The impact of residential density on vehicle usage and energy consumption. Journal of Urban Economics, 65(1), 91-98.

Burton, E. (2000). The compact city: just or just compact? A preliminary analysis. Urban studies, 37(11), 1969-2006.

Cao, X. J. (2009). Disentangling the influence of neighborhood type and self-selection on driving behavior: an application of sample selection model. Transportation, 36(2), 207-222.

Cao, X. J., Mokhtarian, P. L., \& Handy, S. L. (2009). The relationship between the built environment and nonwork travel: A case study of Northern California. Transportation Research Part A: Policy and Practice, 43(5), 548-559.

Cervero, R. (1994). Transit-based housing in California: evidence on ridership impacts. Transport Policy, 1(3), 174-183.

Cervero, R. (2004). Transit-oriented development in the United States: Experiences, challenges, and prospects (Vol. 102). Transportation Research Board.

Cervero, R., \& Guerra, E. (2011). Urban densities and transit: A multi-dimensional perspective. Institute of Transportation Studies, University of California, Berkeley.

Cervero, R., \& Kockelman, K. (1997). Travel demand and the 3Ds: density, diversity, and d esign. Transportation Research Part D: Transport and Environment, 2(3), 199-219.

Chen, C., Gong, H., \& Paaswell, R. (2008). Role of the built environment on mode choice decisions: additional evidence on the impact of density. Transportation, 35(3), 285-299.

Cox, W. (2004). Myths about Urban Growth and the Toronto" Greenbelt". Fraser Institute.

Crane, R. (2000). The Influence of Urban Form on Travel: An Interpretive Review. Journal of Planning Literature, 15(1), 3-23. http://doi.org/10.1177/08854120022092890

Crane, R., \& Crepeau, R. (1998). Does neighborhood design influence travel?: A behavioral analysis of travel diary and GIS data. Transportation Research Part D: Transport and Environment, 3(4), 225-238.

Crane, R., \& Chatman, D. G. (2003). Traffic and Sprawl: Evidence from US Commuting from 1985-1997 (Vol. 6). University of Southern California.

Cutsinger, J., Galster, G., Wolman, H., Hanson, R., \& Towns, D. (2005). Verifying the Multi-Dimensional Nature of Metropolitan Land Use: Advancing the Understanding and Measurement of Sprawl. Journal of Urban Affairs, 27(3), 235259.

Daniels, T. L. (2009). A Trail Across Time: American Environmental Planning From City Beautiful to Sustainability. Journal of the American Planning Association, 75(2), 178-192. http://doi.org/10.1080/01944360902748206 
de la Barra, T. (1989). Integrated Land Use and Transport Modelling. Cambridge: Cambridge University Press.

Department of Transportation. (2011). National household travel survey 2009: Summary of travel trends. Internet online. Accessed March 2016. http://nhts.ornl.gov/2009/pub/stt.pdf

Department of Transportation. (2011). National household travel survey 2009: Summary of travel trends. Internet online. Accessed March 2016. http://nhts.ornl.gov/2009/pub/stt.pdf

Department of Transportation. (2011). National household travel survey 2009: Summary of travel trends. Internet online. Accessed March 2016. http://nhts.ornl.gov/2009/pub/stt.pdf

Department of Transportation. (2009). The 'carbon footprint' of daily travel. NHTS Brief. March 2009. Internet online. Accessed January 2016. http://nhts.ornl.gov/briefs/Carbon\%20Footprint\%20of\%20Travel.pdf

Dieleman, F. M., Dijst, M., \& Burghouwt, G. (2002). Urban Form and Travel Behaviour: Micro-level Household Attributes and Residential Context. Urban Studies, 39(3), $507-527$.

Difiglio, C. \& Fulton, L. (2000). How to reduce US automobile greenhouse gas emissions, Energy, 25, 657-673.

Dijkstra, E. W. (1959). A note on two problems in connexion with graphs. Numerische mathematik, 1(1), 269-271.

Downs, A. (2001). What does "smart growth" really mean. Planning, 67(4), 20-25.

Duany, A., Plater-Zyberk, E., \& Speck, J. (2001). Suburban Nation: The Rise of Sprawl and the Decline of the American Dream. Nw York, NY: North Point Press.

Echenique, M. H. (1994). Urban and regional planning at the Martin Centre: Its origin, its present, and its future. Environmental Planning B, 21(5), 517-533.

Energy Information Administration (EIA). (2008). Emissions of greenhouse gases in the United States 2007. Washington, DC, U.S. Department of Energy. http://www.eia.gov/oiaf/1605/ggrpt/pdf/0573\%282007\%29.pdf

Environmental Protection Agency. (2010). Our nation's air-Status and trends through 2015. Retrieved from: https://www.epa.gov/air-trends.

Environmental Protection Agency. (2012). Draft inventory of US greenhouse gas emissions and sinks: 1990 - 2010. Retrieved from: http://www3.epa.gov/climatechange/Downloads/ghgemissions/US-GHGInventory-2012-Main-Text.pdf.

Environmental Protection Agency. (2016a). Inventory of US greenhouse gas emissions and sinks: 1990 - 2014. Internet online. Accessed March 2016. http://www3.epa.gov/climatechange/Downloads/ghgemissions/US-GHGInventory-2016-Main-Text.pdf

Environmental Protection Agency. (2016b).Summary Nonattainment Area Population Exposure Report. Retrieved from: https://www3.epa.gov/airquality/greenbook/popexp.html

Environmental Protection Agency (EPA). (2006). The master list of compounds emitted by mobile sources. Internet online. Accessed March 2016. 
https://www3.epa.gov/otaq/regs/toxics/420r06005.pdf

Environmental Protection Agency. (2009). Inventory of U.S. greenhouse gas

emissions and sinks: 1990-2007. Internet online. Accessed January 2016.

https://www3.epa.gov/climatechange/Downloads/ghgemissions/GHG2007entire_r eport-508.pdf

Environmental Protection Agency. (2012). Draft inventory of US greenhouse gas emissions and sinks: 1990 - 2010. Internet online. Accessed January 2016. https://www3.epa.gov/climatechange/Downloads/ghgemissions/US-GHGInventory-2014-Main-Text.pdf

Ewing, R. (1997). Is Los Angeles-Style Sprawl Desirable? Journal of the American Planning Association, 63(1), 107-126. http://doi.org/10.1080/01944369708975728

Ewing, R., \& Cervero, R. (2010). Travel and the Built Environment. Journal of the American Planning Association, 76(3), 265-294. http://doi.org/10.1080/01944361003766766

Ewing, R., Pendall, R., \& Chen, D. (2003). Measuring Sprawl and Its Transportation Impacts. Transportation Research Record: Journal of the Transportation Research Board, 1831, 175-183. http://doi.org/10.3141/1831-20

Ewing, R., Rutgers University, Pendall, R., Cornell University, Chen, D. \& Smart Growth America. (2002). Measuring Sprawl and Its Impact. Retrieved from: http://www.smartgrowthamerica.org/documents/MeasuringSprawl.PDF

Farber, S., Maoh, H., \& Kanaroglou, P. (2009). The impacts of urban growth policies on transportation system usage and performance: a simulation approach. Canadian Journal of Transportation, 3(1).

Farr, D. (2008). Sustainable urbanism: urban design with nature. Wiley, Hoboken.

Frank, L., Chapman, J., Bradley, M., \& Lawton, T. K. (2005). Travel Behavior, Emissions \& Land Use Correlation Analysis in the Central Puget Sound (No. WA-RD 625.1).

Frank, L. D., Greenwald, M. J., Kavage, S., \& Devlin, A. (2011). An assessment of urban form and pedestrian and transit improvements as an integrated GHG reduction strategy (No. WA-RD 765.1).

Frank, L.D., \& Pivo, P. (1994). Relationships between land use and travel behavior in the Puget Sound Region, Washington State DOT, WA-RD 351.1. Retrieved on February, 2016: http://www.wsdot.wa.gov/research/reports/fullreports/351.1.pdf

Frank, L. D., Stone, B., \& Bachman, W. (2000). Linking land use with household vehicle emissions in the central Puget Sound: methodological framework and findings. Transportation Research Part D: Transport and Environment, 5(3), 173-196.

Gallivan, F., Rose, E., Ewing, R., Hamidi, S., \& Brown, T. (2015). Quantifying Transit's Impact on GHG Emissions and Energy Use-The Land Use Component (No. Project $\mathrm{H}-46)$.

Galster, G., Hanson, R., Ratcliffe, M. R., Wolman, H., Coleman, S., \& Freihage, J. (2001). Wrestling Sprawl to the Ground: Defining and measuring an elusive concept. Housing Policy Debate, 12(4), 681-717. http://doi.org/10.1080/10511482.2001.9521426 
Giuliano, G. \& Narayan, D. (2003). Another look at travel patterns and urban form: The US and Great Britain, Urban studies, 40(11), 2295-2312.

Glaeser, E. L., \& Kahn, M. E. (2001). Decentralized employment and the transformation of the American city (No. w8117). National Bureau of Economic Research.

Glaeser, E. L., \& Kahn, M. E. (2010). The greenness of cities: carbon dioxide emissions and urban development. Journal of urban economics, 67(3), 404-418.

Glaeser, E. L., Kahn, M. E., \& Rappaport, J. (2008). Why do the poor live in cities? The role of public transportation. Journal of urban Economics, 63(1), 1-24.

Gomez-Ibanez, J. (1991). A Global Review of Automobile Dependence (Book Review). Journal of the American Planning Association, 57, 342-346.

Gordon, P., Kumar, A., \& Richardson, H. W. (1989). The influence of metropolitan spatial structure on commuting time. Journal of Urban Economics, 26(2), 138151.

Gordon, P., \& Richardson, H. W. (1997). Are Compact Cities a Desirable Planning Goal? Journal of the American Planning Association, 63(1), 95-106. http://doi.org/10.1080/01944369708975727

Grazi, F., \& van den Bergh, J. C. J. M. (2008). Spatial organization, transport, and climate change: Comparing instruments of spatial planning and policy. Ecological Economics, 67(4), 630-639. http://doi.org/10.1016/j.ecolecon.2008.01.014

Greene, W. (2012). Econometric Analysis (7th ed.). Upper Saddle River, NJ: Prentice Hall. Retrieved from http://www.amazon.de/exec/obidos/redirect?tag=citeulike0121\&path=ASIN/0131108492

Greenwald, M. J. (2003). The road less traveled: New urbanist inducements to travel mode substitution for nonwork trips. Journal of Planning Education and Research, 23(1), 39-57.

Greenwald, M., \& Boarnet, M. (2001). Built environment as determinant of walking behavior: Analyzing nonwork pedestrian travel in Portland, Oregon.

Transportation Research Record: Journal of the Transportation Research Board, (1780), 33-41.

Hall, P. (2002). Cities of tomorrow: an intellectual history of urban planning and design in the twentieth century, 3rd edn. Basil Blackwell, Oxford.

Handy, S. (1996). Methodologies for Exploring the Link between Urban Form and Travel Behavior. Transportation Research Part D: Transport and Environment, 1,151165.

Handy, S. (2005). Smart growth and the transportation-land use connection: What does the research tell us? International Regional Science Review, 28(2), 146167.Hankey, S., \& Marshall, J. D. (2010). Impacts of urban form on future US passenger vehicle greenhouse gas emissions. Energy Policy, 38(9), 4880-4887.

Handy, S., Tal, G., \& Boarnet, M. (2010). Draft Policy Brief on the Impacts of Regional Network Connectivity Based on a Review of the Empirical Literature, for Reserch on Impacts of transportaon and Land Use-Related Policies. California Air Resources Board. 
Heanue, K. (1997). Transportation S\&T Strategy Partnership Initiatives. A presentation to the National Science and Technology Council, Transportation Research and Development Committee, September 25, Washington, DC.

Heckman, J. (1979). Sample selection bias as a specification error. Econometrica, 47(1), $153-162$.

Heres-Del-Valle, D., \& Niemeier, D. (2011). CO 2 emissions: Are land-use changes enough for California to reduce VMT? Specification of a two-part model with instrumental variables. Transportation Research Part B, 45(1), 150-161. http://doi.org/10.1016/j.trb.2010.04.001

IBI Group. (1990). Greater Toronto Area Urban Structure Concept Study, 9 vols. Prepared for the Greater Toronto Coordinating Committee.

IPCC (2013). Climate Change 2013: The Physical Science Basis. Contribution of Working Group I to the Fifth Assessment Report of the Intergovernmental Panel on Climate Change [Stocker, T.F., D. Qin, G.-K. Plattner, M. Tignor, S.K. Allen, J. Boschung, A. Nauels, Y. Xia, V. Bex and P.M. Midgley (eds.)]. Cambridge: Cambridge University Press.

Jenks, M., Burton E. \& Williams, K. (1996). Compact cities and sustainability. In The compact city: a sustainable urban form? Jenks, M., Burton E., Williams, K. (Eds.), The Compact City: A Sustainable Urban Form? London, E\&FN SPON.

Jo, H. K., \& McPherson, G. E. (1995). Carbon storage and flux in urban residential greenspace. Journal of Environmental Management, 45(2), 109-133.

Kenworthy, J. R. (2006). The eco-city: ten key transport and planning dimensions for sustainable city development. Environment and Urbanization, 18(1), 67-85. http://doi.org/10.1177/0956247806063947

Khan, M., Kockelman, K. M., \& Xiong, X. (2014). Models for anticipating nonmotorized travel choices, and the role of the built environment. Transport Policy, 35, 117-126.

Knaap, G. J., Song, Y., Ewing, R., \& Clifton, K. (2005). Seeing the elephant: multidisciplinary measures of urban sprawl. National Center for Smart Growth Research and Education, Urban Studies and Planning Program, University of Maryland.

Krizek, K. J. (2003). Residential Relocation and Changes in Urban Travel: Does Neighborhood-Scale Urban Form Matter? Journal of the American Planning Association, 69(3), 265-281. http://doi.org/10.1080/01944360308978019

Kulash, W., Anglin, J., \& Marks, D. (1990). Traditional Neighborhood Development: Will the Traffic Work? Development, 21:4-21.

Leontief, W. W. (1951). Input-output economics. Scientific America, 185(4), 15-21.

Litman, T. (2005). Land use impacts on transport. Victoria Transport Policy Institute (www. vtpi. org).

Litman, T. (2007). Developing indicators for comprehensive and sustainable transport planning. Transportation Research Record: Journal of the Transportation Research Board, (2017), 10-15.

Lowry, I.S. (1964). A Model of Metropolis. RM-4035-RC. Rand Corporation, Santa Monica, CA. 
Lucas, P. (2009). Usefulness of Simulating Social Phenomena. In Proceedings of the AISB 2009 Convention. Edinburgh, Scotland.

Malpezzi, S. (1999). Estimates of the measurement and determinants of urban sprawl in US metropolitan areas (No. 99-06). University of Wisconsin Center for Urban Land Economic Research.

Mansfield, T. J., Rodriguez, D. A., Huegy, J., \& MacDonald Gibson, J. (2015). The effects of urban form on ambient air pollution and public health risk: a case study in raleigh, north Carolina. Risk Analysis, 35(5), 901-918.

Manville, M., \& Shoup, D. (2005). Parking, people, and cities. Journal of Urban Planning and Development, 131(4), 233-245.

McFadden, D. (1974). Conditional logit analysis of qualitative choice behaviour. In P. Zarembka (ed.), Frontiers in Econometrics. New York,NY: Academic Press.

Mindali, O., Raveh, A., \& Salomon, I. (2004). Urban density and energy consumption: a new look at old statistics. Transportation Research Part A: Policy and Practice, 38(2), 143-162. http://doi.org/10.1016/j.tra.2003.10.004

Miller, E., \& Ibrahim, A. (1998). Urban form and vehicular travel: some empirical findings. Transportation Research Record: Journal of the Transportation Research Board, (1617), 18-27.

Mitchell, G., Hargreaves, A., Namdeo, A., \& Echenique, M. (2011). Land use, transport, and carbon futures: the impact of spatial form strategies in three UK urban regions. Environment and Planning A, 43(9), 2143-2163.

Montgomery, J. (1998). Making a city: Urbanity, vitality and urban design. Journal of Urban Design, 3(1), 93-116. http://doi.org/10.1080/13574809808724418

Mumford, L.(1968). The urban prospect. Secker and Warbug, London.

Næss, P. (2006). Accessibility, Activity Participation and Location of Activities: Exploring the Links between Residential Location and Travel Behaviour. Urban Studies, 43(3), 627-652.

Næss, P., Røe, P. G., \& Larsen, S. (1995). Travelling Distances, Modal Split and Transportation Energy in Thirty Residential Areas in Oslo. Journal of Environmental Planning and Management, 38(3), 349-370.

Newbold, K. B., Scott, D. M., Spinney, J. E. L., Kanaroglou, P., \& Paez, A. (2005). Travel behavior within Canada's older population: a cohort analysis. Journal of Transport Geography, 13(4), 340-351.

Neuman, M. (2005). The compact city fallacy. Journal of planning education and research, 25(1), 11-26.

Newman, P. W. G., \& Kenworthy, J. R. (1989). Gasoline Consumption and Cities: A Comparison of U.S. Cities with a Global Survey. Journal of the American Planning Association, 55(1), 24-37. http://doi.org/10.1080/01944368908975398

Owen, D. (2009). Green metropolis: why living smaller, living closer, and driving less are the keys to sustainability. New York, NY: Riverhead Hardcover.

Popper, K. R. (1959). The logic of scientific discovery. London: Hutchinson.

Pushkar, A. O., Hollingworth, B. J., \& Miller, E. J. (2000). A multivariate regression model for estimating greenhouse gas emissions from alternative neighborhood 
designs. In 79th annual meeting of the Transportation Research Board, Washington, DC.

Roy, A. D. (1951). Some thoughts on the distribution of earnings. Oxford economic papers, 3(2), 135-146.

Ryley, T. (2006). Use of non-motorised modes and life stage in Edinburgh.Journal of Transport Geography, 14(5), 367-375.

Schiller, P. L., Bruun, E. C., \& Kenworthy, J. R. (2010). An introduction to sustainable transportation: Policy, planning and implementation. London: Earthscan.

Schwanen, T., \& Mokhtarian, P. L. (2005). What if you live in the wrong neighborhood? The impact of residential neighborhood type dissonance on distance traveled. Transportation Research Part D: Transport and Environment, 10(2), 127-151.

Schwarz, N. (2010). Urban form revisited-Selecting indicators for characterising European cities. Landscape and Urban Planning, 96(1), 29-47. http://doi.org/10.1016/j.landurbplan.2010.01.007

Shen, Q. (2000). Spatial and Social Dimensions of Commuting. Journal of the American Planning Association, 66, 68-82.

Slavin, M. I. (2011). The rise of the urban sustainability movement in America. In Sustainability in America's Cities (pp. 1-19). Island Press/Center for Resource Economics.

StataCorp. (2013). Stata Statistical Software: Release 13. College Station, TX: StataCorp LP.

Stead, D. (1999). Relationships between transport emissions and travel patterns in Britain. Transport Policy, 6(4), 247-258. http://doi.org/10.1016/S0967070X(99)00025-6

Stone Jr, B., Mednick, A. C., Holloway, T., \& Spak, S. N. (2007). Is compact growth good for air quality?. Journal of the American Planning Association, 73(4), 404418.

Stone Jr, B., Mednick, A. C., Holloway, T., \& Spak, S. N. (2009). Mobile source CO2 mitigation through smart growth development and vehicle fleet hybridization. Environmental science \& technology, 43(6), 1704-1710.

Sultana, S. (2000). Some effects of employment centers on commuting times in the Atlanta metropolitan area, 1990. Southeastern Geographer, 40(2), 225-233.

Susilo, Y. O., \& Maat, K. (2007). The influence of built environment to the trends in commuting journeys in the Netherlands. Transportation, 34(5), 589-609.

Tabachnick, B. G., \& Fidell, F. S. (2013). Using Multivariate Statistics (6th ed.). Upper Saddle River, New Jersey: Pearson.

The Sierra Club. (1998). The dark side of the American dream: the costs and consequences of suburban sprawl. The Sierra Club, San Francisco.

Torrens, P.M., Alberti, M., (2000). Measuring sprawl. Working paper no. 27, Centre for Advanced Spatial Analysis, University College,

London.(http://www.casa.ac.uk/workingpapers/)

Transportation Research Board. (2009). Driving and the Built Environment: The Effects of Compact Development on Motorized Travel, Energy Use, and CO2 Emissions. Special Report 298. Washington, DC: Transportation Research Board. 
Wang, X., Khattak, A., \& Zhang, Y. (2013a). Is Smart Growth Associated with Reductions in Carbon Dioxide Emissions? Transportation Research Record: Journal of the Transportation Research Board, 2375, 62-70. http://doi.org/10.3141/2375-08

Wang, X., Khattak, A., \& Chen, J. (2013b). Accuracy of Geoimputation: An Approach to Capture Microenvironment. Transportation Research Record: Journal of the Transportation Research Board, (2382), 10-19.

Wilson, A. G. (1970). Inter-regional Commodity Flows: Entropy Maximizing Approaches. Geographical Analysis, 2(3), 255-282.

Woldeamanuel, M., \& Kent, A. (2014). Determinants of per capita vehicle miles traveled (VMT): The case of California. Journal of the Transportation Research Forum, 53 (3), 35-46).

Wooldridge, J. M. (2010). Econometric Analysis of Cross Section and Panel Data. MIT Press.

World Commission on Environment and Development. (1987). Our common future. Oxford University Press, Oxford.

Ye, Lin, Sumedha Mandpe, and Peter Meyer. (2005). "What is Smart Growth?-Really?" Journal of Planning Literature, 19 (3): 301-315.

Zolnik, E. J. (2011). The effect of sprawl on private-vehicle commuting outcomes. Environment and Planning A, 43(8), 1875-1893. 